\title{
Sinkhole susceptibility mapping: a comparison between Bayes-based machine learning
}

\section{algorithms}

Kamal Taheri ${ }^{1}$, Himan Shahabi ${ }^{2,}{ }^{*}$, Kamran Chapi ${ }^{3}$, Ataollah Shirzadi ${ }^{3}$, Francisco Gutiérrez ${ }^{4}$, Khabat Khosravi $^{5}$

${ }^{I}$ Karst Research and Study Office of Western Iran, Kermanshah Regional Water Authority,

\section{Department \\ Kermanshah, Iran}

${ }^{2}$ Department of Geomorphology, Faculty of Natural Resources, University of Kurdistan, Sanandaj, Iran

${ }^{3}$ Department of Rangeland and Watershed Management, Faculty of Natural Resources, University of Kurdistan, Sanandaj, Iran

${ }^{4}$ Earth Science Department, Edificio Geológicas, Universidad de Zaragoza, Zaragoza, Spain

${ }^{5}$ Department of Watershed Sciences Engineering, Faculty of Natural Resources, University of Agricultural Science and Natural Resources of Sari, Mazandaran, Iran

*Corresponding Author: Himan Shahabi, Department of Geomorphology, Faculty of Natural Resources, University of Kurdistan, Sanandaj, Iran, E-mail: h.shahabi@uok.ac.ir Tel: +989186658739

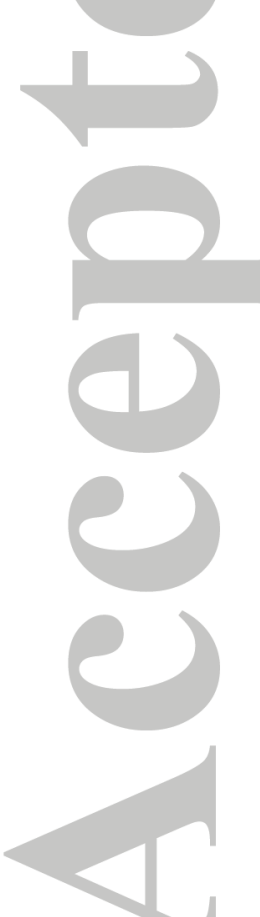

This article has been accepted for publication and undergone full peer review but has not been through the copyediting, typesetting, pagination and proofreading process which may lead to differences between this version and the Version of Record. Please cite this article as doi: $10.1002 / \mathrm{ldr} .3255$ 


\begin{abstract}
Land degradation has been recognized as one of the most adverse environmental impacts during the last century. The occurrence of sinkholes is increasing dramatically in many regions worldwide contributing to land degradation. The rise in the sinkhole frequency is largely due to human-induced hydrological alterations that favour dissolution and subsidence processes. Mitigating detrimental impacts associated with sinkholes requires understanding different aspects of this phenomenon such as the controlling factors and the spatial distribution patterns. This research illustrates the development and validation of sinkhole susceptibility models in Hamadan Province, Iran, where a large number of sinkholes are occurring under poorly understood circumstances. Several susceptibility models were developed with a training sample of sinkholes, a number of conditioning factors and four different statistical approaches: Naïve Bayes (NB), Bayes Net (BN), Logistic Regression (LR), and Bayesian Logistic Regression (BLR). Ten conditioning factors were initially considered. Factors with negligible contribution to the quality of predictions, according to the information gain ratio (IGR) technique, were discarded for the development of the final models. The validation of susceptibility models, performed using different statistical indices and ROC-curves, revealed that the BN model has the highest prediction capability in the study area. This model provides reliable predictions on the future distribution of sinkholes, which can be used by watershed and land-use managers for designing hazard and landdegradation mitigation plans.
\end{abstract}

Keywords: Sinkhole, Naïve Bayes, Bayes Net, Logistic Regression, Iran 


\section{INTRODUCTION}

Land degradation is a major problem worldwide, especially in developing countries, due mainly to the improper use of land, soil and water resources (Jafari \& Bakhshandehmehr, 2016; Symeonakis et al., 2016). Land degradation is generally attributed to human activities that cause detrimental effects upon the land, typically involving reduction in its productive capacity (Minaei et al., 2018). Sinkholes are considered as the most characteristic landform in karst terrains, which represent around $20 \%$ of the continental surface (Ford \& Williams, 2013). Sinkholes, like other geohazards, are generally viewed as natural phenomena rather than as a land-degradation agent. However, extensive literature on the subject reveals that a large proportion of the new sinkholes are human-induced (e.g., Parise, 2013; Bui et al., 2018b). Anthropogenic activities such as groundwater withdrawal, irrigation, dewatering for mining or diversion of river flow, are increasing the frequency of sinkholes in many regions worldwide (Filippi \& Bosák, 2013; Parise, 2013; Vattano et al., 2013; Gutiérrez et al., 2014; Chen et al., 2017; Tien Bui et al., 2018). The formation of sinkholes involves the reduction of agricultural land, may significantly compromise safety, cause severe damage to infrastructure, and in extreme cases may result in the abandonment of agricultural areas and irrigation plans (Gunn, 2004; Hyland, 2005). Overall, the impacts associated with sinkholes are particularly severe in arid areas, where the exploitation of water resources for irrigation leads to rapid hydrological changes (e.g., water-table decline, sharp increase in water infiltration) that contribute to trigger sinkholes. In many of these areas, groundwater overexploitation and the consequent decline in the water table, together with the onset of irrigation plans, are triggering subsidence processes over pre-existing cavities (Youssef et al., 2016). During the last two decades, groundwater over-exploitation in some regions of Iran, especially in plains with semi-arid climate, has resulted in the development of a large number of hazardous sinkholes (Heidari et al., 2011; Taheri et al., 2015). For instance, in the Hamadan central plain, which is the focus of this study, groundwater pumping has triggered the development of over 47 sinkholes between 1988 and 2006, creating a high risk scenario for some sensitive areas and infrastructure (Heidari et al., 2011).

In order to mitigate the detrimental consequences of sinkholes, it is of great importance to develop approaches aimed at quantitatively assessing the factors that control the subsidence phenomena and predicting their spatial distribution. Sinkhole susceptibility maps (SSMs) developed and validated through statistical approaches provides a spatially continuous and easily accessible tool for managing sinkhole hazards (Galve et al., 2009). Recently, several statistical approaches have been applied to the development of SSMs in a GIS environment, 
including analytic hierarchy processes (Taheri et al., 2015), frequency ratio (Yilmaz, 2007), logistic regression (Papadopoulou-Vrynioti et al., 2013; Ciotoli et al., 2016), artificial neural networks (Yilmaz et al., 2013), and conditional probability (Yilmaz et al., 2013). These methods provide susceptibility assessments that are objective, reproducible and may reach a high spatial resolution (Chen et al., 2014). Moreover, high prediction rates have been demonstrated in some regions (Shirzadi et al., 2017b). However, it is highly necessary to explore new approaches for sinkhole susceptibility mapping and assess comparatively the performance of different methods, since any increment in the reliability of the predictions would have a positive impact on the effectiveness of mitigation plans.

Various machine learning algorithms (MLAs) have been recently developed for analyzing complex environmental problems that entail land degradation such as sinkholes. The main advantage of the MLAs is their ability to analyze complex relationships among large datasets. Additionally, the MLAs can deal with spatial patterns of data at various scales (Kanevski et al., 2004). The application of these new machine learning predictive models has been explored in different geoscience fields including landsides (Chen et al., 2015; Chen et al., 2016; Chen et al., 2017a; Hong et al., 2017), groundwater qanat potential (Naghibi et al., 2017), or land subsidence (Pradhan et al., 2014). However, their application to sinkhole susceptibility modelling is still very limited. MLAs have a high computational efficiency, despite the fact that the models produced with these statistical approaches may have limited prediction capability and utility related to multiple factors such as the quantity and quality of the data (epistemic uncertainty) and the inherent spatial-temporal patterns of the phenomenon and controlling factors (aleatory uncertainty) (Bui et al., 2018a; Bui et al., 2018b; Shafizadeh-Moghadam et al., 2018). Therefore, identifying the algorithm that allows developing the best-quality susceptibility models is a critical issue to effectively manage risk and land-degradation problems associated with sinkhole activity. Hence, the main target of this study is to evaluate and compare the performance of Naïve Bayes (NB), Bayes Net (BN), Logistic Regression (LR), and Bayesian Logistic Regression (BLR) classifier models for sinkhole susceptibility mapping in the northern plains of Hamadan province, Iran. To our best knowledge, these algorithms have not been applied to sinkhole susceptibility mapping before.

\section{STUDY AREA}

The study area includes the Kabudar Ahang and the Razan-Qahavand subcatchments (KRQ) of the Hoz-e-soltan of Qom watershed, in the northern Hamadan Province, western Iran (Figure 1). It covers an area of $6,532 \mathrm{~km}^{2}$, of which $3,402 \mathrm{~km}^{2}(52 \%)$ correspond to alluvial 
plains and piedmonts. Mean elevation is $1715 \mathrm{~m}$ and climate is semi-arid, with $300 \mathrm{~mm}$ average annual precipitation and a mean temperature of $10.5^{\circ} \mathrm{C}$ (Sabziparvar, 2003).

\section{(Figure 1)}

From the geological perspective, the Zagros orogenic belt consists of four main NW-SE trending structural zones, from NE to SW: Urumieh-Dokhtar Magmatic Assemblage, Sanandaj-Sirjan, High Zagros Belt, and Zagros Simply Folded Belt (Ghasemi \& Talbot, 2006). The study area is situated within the Sanandaj-Sirjan structural zone, in which the rocks show the highest degree of deformation of this active orogene (Figure 2). The exposed bedrock consists of a thick Jurassic to Miocene succession including sedimentary and volcanic rocks affected by folds and thrusts with a dominant NW-SE trend. The Jurassic succession is made up of recrystallized limestone, shales, sandstones, marls with limestone intercalations and conglomerates. The Cretaceous units also include limestones, dolostones and detrital formations. The Eocene Karaj Formation mainly consists of volcanic rocks (andesite, dacite, green tuff). The so-called "lower red formation" of Oligocene age is made up of marls and some sandstones and limestones. The main aquifer is the Oligo-Miocene-age Qom Formation, which is dominated by limestone as well as volcanic rocks (andesite, tuff, basalt). This karstified limestone is best exposed around Hamakasi village and the Mount Qoli Abad. The Miocene "upper red formation" is dominantly a detrital unit. The area also includes sparse outcrops of late Pliocene and probably Pleistocene lava flows that record recent volcanic activity in the area. Sinkholes in Hamedan area mainly occur in Quaternary alluvial deposits underlain by the karstified Qom limestone (Heidari et al., 2011; Taheri et al., 2015). Interestingly, according to borehole and geophysical data, the Quaternary alluvium in areas affected by recent sinkhole development reaches as much as $150 \mathrm{~m}$ in thickness. The alluvium shows an overall thickness increase towards the central parts of the synclinal basins, indicative of syntectonic deposition. Borehole data show that the alluvial cover is dominated by cohesive fine-grained facies, although they grade into coarser deposits (proximal facies) towards the mountain ranges.

Previous investigations demonstrate that the recent occurrence of numerous sinkholes in the area is related to groundwater over-exploitation and the associated water table decline (e.g., Khanlari et al., 2012). This anthropogenic change in the local hydrological conditions has favored the internal erosion of cover deposits into significant pre-existing cavities. This process results in the progressive upward stopping of voids through the thick and cohesive 
overburden and the development of sudden cover-collapse sinkholes, which is the main sinkhole type in the area. Some authors also propose that limestone karstification in the groundwater discharge areas is fostered by renewed aggressiveness due to the incorporation of deep magmatic fluids along fractures into the flow system. This is supported by the presence of $\mathrm{CO}_{2}$-rich springs that emerge from the Qom Formation in the vicinity of Hamakasi village. About $80 \%$ of the public-production wells in the area are located in alluvial deposits, and only $20 \%$ penetrate into the karst aquifer. The water balance for the KRQ alluvial aquifer indicates that around $95 \%$ of the recharge is related to irrigation. These are critical factors that govern groundwater level fluctuations over seasonal and long-term scales.

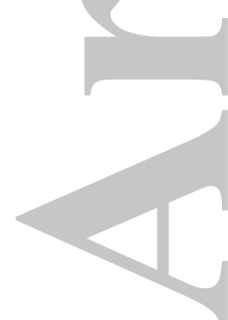

(Figure 2)

\section{Data acquisition}

\section{DATA AND METHODS}

\section{Sinkhole inventory map (SIM)}

The SIM was constructed following two steps: (1) field-based sinkhole identification and recording of their locations, typology, chronology and morphometric parameters, such as major axial length (D) and depth, and (2) production of a georeferenced sinkhole map. The inventory includes 47 sinkholes occurred over a period of 22 years (1988-2010) reported by Taheri et al. (2015). Sinkholes were categorized as cover-collapse sinkholes (86\%) and solution sinkholes (14\%) (Karimi \& Taheri, 2010).

The major axial length ranges from $1.5 \mathrm{~m}$ to $100 \mathrm{~m}$, with an average value of $14.4 \mathrm{~m}$ and a standard deviation of $16.7 \mathrm{~m}$. Average depth is $6.2 \mathrm{~m}$ and sinkholes tend to be subcircular, although reach a maximum elongation ratio (major axial length/minor axial length) of 6 . Maximum estimated volume is greater than $20,000 \mathrm{~m}^{3}$ and around $40 \%$ of the sinkholes exceed $1000 \mathrm{~m}^{3}$ in volume (Taheri et al., 2015). Size and frequency relationships of the sinkholes using the available chronological data indicate maximum recurrence intervals of $1.2,2.1$ and 4.2 years for sinkholes with lengths of 10, 20 and $30 \mathrm{~m}$, respectively (Taheri et $a l ., 2015)$. For the development of susceptibility models, the 47 sinkholes were randomly divided into training (32 sinkholes) and validation (15 sinkholes) datasets. Furthermore, the same number of grid cells without sinkholes were randomly selected and partitioned into training and validation datasets. Table 1 shows the relevant information on the sinkholes inventoried in the study area. 
(Table 1)

\section{Field investigation}

In this study, initially we gathered information on the location of sinkholes from the Hamadan Regional Water Authority (HRWA) and each of these sites were checked in the field. The field surveys in the current study included (i) recording of sinkhole location and characteristics, (ii) sampling of deposits and bedrock units, and (iii) identification of features related to some conditioning factors (e.g., rock units, faults) (Taheri et al., 2015).

\section{Sinkhole conditioning factors}

The production of sinkhole susceptibility maps was based on the spatial relationships between the sinkholes of the training dataset and a number of potential conditioning factors. Thematic maps of ten conditioning factors were produced, which can be divided into three categories (Figure 3): (1) hydrogeological factors; (2) geological factors; and (3) anthropogenic factors. Hydrogeological factors include water level decline (WLD), penetration of deep wells into the karst aquifer (PKA), distance to deep wells (DDW), and groundwater alkalinity (GA). The geological factors refer to bedrock lithology (BL), alluvial thickness (AT), distance to faults (DF), and fault density (FD). Groundwater exploitation (GE) and land use (LU) are the anthropogenic factors considered in this study. Table 2 shows the factors used for sinkhole susceptibility assessment and data sources. We selected these factors based on data availability, literature reviews (mainly Taheri et al., 2015), and expert knowledge.

\section{Water level decline $(W L D)$}

WLD plays an important role in the formation of human-induced sinkholes (Newton, 1984; Gutiérrez et al., 2016). Data from 65 piezometers covering a 22-year record period (19882010) were used to construct the WLD map by the inverse distance weighted (IDW) method and differentiating six categories of WLD in meters (Figure $3 a$ ).

\section{Groundwater exploitation (GE)}

GE accounts for the rate of groundwater pumping from wells in $\mathrm{Mm}^{3}$ per year. It provides information on the distribution of groundwater withdrawal points and their relative importance. The data base of the HRWA, including records from 3,850 wells, was utilized for 
the preparation of the GE map using the IDW method and discretizing the variable into six categories (Figure 3b).

Penetration of deep wells into karst aquifer (PKA)

PKA indicates the vertical distance between the top of the bedrock and the bottom of deep wells. It seems to play a major role in the formation of sinkholes in the study area, especially in the vicinity of Hamadan Power Plant. The PKA map was produced by the IDW method and differentiated six categories (Figure 3c).

\section{Distance to deep wells (DDW)}

A significant proportion of the reported sinkholes are situated in the proximity of deep wells mainly drilled by local residents. The incorporation of this factor in the analysis relies on the hypothesis that the probability of sinkhole occurrence is inversely proportional to the distance of each point to the nearest deep well. The DDW map was constructed by a buffering method and discretizing the variable into six classes (Figure 3d).

\section{Groundwater alkalinity (GA)}

$\mathrm{GA}$ is defined as the total concentration of bicarbonate $\left(\mathrm{HCO}^{-}\right)$and carbonate $\left(\mathrm{CO}_{3}{ }^{2-}\right)$ ions (Bowman, 1997), reflecting the capability of the water to corrode limestone bedrocks and the carbonate components of overburden deposits. In general, the higher the alkalinity is, the lower the aggressiveness of the water will be. The concentration of bicarbonate in the typical karstic groundwater is around $200 \mathrm{mg} / \mathrm{l}$ (Salvati \& Sasowsky, 2002), whereas in some parts of the KRQ it exceeds $1500 \mathrm{mg} / \mathrm{l}$. The GA map was produced by discretizing this continuous variable into six intervals using the natural break method (Figure $3 \mathrm{e}$ ).

\section{Bedrock lithology $(B L)$}

$\mathrm{BL}$ is a critical factor for the distribution of sinkholes, since a prerequisite for their formation is the presence of soluble bedrock. Nonetheless, most of the sinkholes occur in areas extensively covered by Quaternary alluvium, where there is significant uncertainty about the distribution of the different lithologies that form the rockhead (Heidari et al., 2011). Five lithotypes have been differentiated in the BL map: schist-shale, marl, limestone, marly limestone and conglomerate-sandstone (Figure 3f). 
Alluvial thickness (AT)

A striking characteristic of this area is that sinkholes occur in zones where the limestone bedrock is covered by a very thick alluvial cover, locally more than $100 \mathrm{~m}$ thick (Taheri et $a l ., 2015)$. This indicates that deep cavities developed in the bedrock can propagate upwards by progressive collapse through thick alluvium. The AT map has been generated with the available borehole data and dividing the variable into six classes by the natural break method (Figure 3g).

\section{Distance to faults $(D F)$}

The relative spatial distribution of sinkholes and major faults, as well as some patterns like the elongation and alignment of some sinkholes suggest that the cavities and the associated subsidence processes may be controlled by tectonic structures (Taheri et al., 2016). The DF map was produced with the faults depicted in the available 1:100,000 scale geological maps and categorizing the resulting values into six classes (Figure $3 \mathrm{~h}$ ). The faults used in the analysis, mostly with reverse displacement, where checked during the field surveys.

\section{Fault density (FD)}

Fault density refers to the cumulative length of faults per unit area (Shirzadi et al., 2017a). A high density of faults in carbonate bedrock may create favorable permeability conditions for groundwater circulation, the creation of structurally-controlled cavities and the occurrence of sinkholes. The fault density was calculated using data from the 1:100,000 scale geological map and was grouped into six classes (Figure 3i).

\section{Land use (LU)}

The type of land use may significantly influence some processes involved in sinkhole development by modifying the natural hydrology and vegetation, notably internal erosion and cover collapse. The LU map was produced using Operational Land Imager (OLI)-sensor images captured by Landsat 8 satellite on 10 August 2013 and provided by the National Geographical Service of Iran. The land-use map differentiates five classes including dry farming, rocky land, rangeland, irrigated farming and barren land. The land-use classes were mapped by means of supervised Maximum Likelihood Classification (MLC) using the ENVI5.1 software (Figure 3j). The resulting normalized difference vegetation index (NDVI) 
map shows the distribution of different vegetation coverages. This index is between -1 to +1 and was calculated by the following equation (Pradhan et al., 2010):

$\mathrm{NDVI}=(\mathrm{NIR}-\mathrm{VIS}) /(\mathrm{NIR}+\mathrm{VIS})$

(1)

where VIS and NIR are the spectral reflectance acquired in the red band and near-infrared band, respectively.

\section{(Figure 3)}

(Table 2)

\section{Factor selection based on the information gain ratio}

Sinkhole occurrence depends on favorable conditions determined by a number of local factors. Consequently, selecting the factors with higher predictive ability is a critical step in susceptibility modeling (Pradhan, 2013). In order to increase the prediction capability of the models and the benefit/effort ratio of the data-gathering and modeling process, the factors with low or null predictive capability should be removed (Doshi, 2014). These factors can be identified through the information gain ratio method (IGR) (Quinlan, 1996).

Consider $\mathrm{S}$ as a training dataset consisting of $\mathrm{n}$ input samples, where $\mathrm{n}\left(\mathrm{Y}_{\mathrm{i}}, \mathrm{S}\right)$ is the number of samples in the training dataset $\mathrm{S}$, belonging to the $\mathrm{Y}_{\mathrm{i}}$ class (sinkhole, no-sinkhole). The IGR for a sinkhole conditioning factor such as alluvial thickness (AT) and the training data (S) is given by:

$$
\operatorname{IGR}(\mathrm{S}, \mathrm{AT})=\frac{\text { Entropy }(\mathrm{S})-\text { Entropy }(\mathrm{S}, \mathrm{AT})}{\text { SplitEntropy }(\mathrm{S}, \mathrm{AT})}
$$

(2)

$$
\text { Entropy }(\mathrm{S})=-\sum_{\mathrm{i}=1}^{2} \frac{\mathrm{n}\left(\mathrm{Y}_{\mathrm{i}}, \mathrm{AT}\right)}{|\mathrm{S}|} \log _{2} \frac{\mathrm{n}\left(\mathrm{Y}_{\mathrm{i}}, \mathrm{AT}\right)}{|\mathrm{S}|}
$$

$$
\operatorname{Entropy}(S, A T)=\sum_{j=1}^{m} \frac{S_{j}}{|S|} \operatorname{Entropy}(S)
$$


SplitEntropy $(S, A T)=-\sum_{\mathrm{j}=1}^{\mathrm{m}} \frac{\left|S_{\mathrm{j}}\right|}{|S|} \log _{2} \frac{\left|S_{\mathrm{j}}\right|}{|S|}$

(5)

Background on the machine learning algorithms

Naïve Bayes (NB) classifier

NB is a Bayes-based classifier based on conditional independence (CI) (Pham et al., 2017). In CI, it is assumed that all attributes of examples are independent for maximizing the posterior probability with given output class for classification issue (Soni et al., 2011). The main aim of the NB classifier is to compute the prior probabilities of each class using a discriminant function (Hong et al., 2017). NB has been applied in many scientific fields because it is very robust to noise and irrelevant attributes and also does not need a big training dataset for modeling (Tien Bui et al., 2012). For mapping sinkhole susceptibility using the $\mathrm{NB}$ classifier, it was considered $x=\left(x_{1}, x_{2}, \ldots, x_{10}\right)$ as the vector of the ten conditioning factors and $y=\left(y_{1}, y_{2}\right)$ as the vector of the dependent variables (sinkhole, nosinkhole). The prior probability of NB is obtained using a discriminant function as follows:

$$
\begin{gathered}
\mathrm{y}_{\mathrm{NB}}=\underset{\mathrm{y}_{\mathrm{i}}=[\text { sinkhole,no-sinkhole }]}{\operatorname{argmax}}\left(\mathrm{y}_{\mathrm{i}}\right) \prod_{\mathrm{i}=1}^{10} \mathrm{P}\left(\mathrm{x}_{\mathrm{i}} \mid \mathrm{y}_{\mathrm{i}}\right) \\
\end{gathered}
$$

(6)

where $\mathrm{P}\left(\mathrm{y}_{\mathrm{i}}\right)$ is prior probability of $\mathrm{y}_{\mathrm{i}}$, and $\mathrm{P}\left(\mathrm{x}_{\mathrm{i}} \mid \mathrm{y}_{\mathrm{i}}\right)$ is the conditional probability obtained using the following equation:

$$
\mathrm{P}\left(\mathrm{x}_{\mathrm{i}} \mid \mathrm{y}_{\mathrm{i}}\right)=\frac{1}{\sqrt{2 \pi \alpha}} e^{\frac{-\left(x_{i}-\eta\right)}{2 \alpha^{2}}}
$$

where $\eta$ and $\alpha$ are the mean and standard deviation of $\mathrm{X}_{\mathrm{i}}$, respectively.

\section{Bayes Net (BN) classifier}

$\mathrm{BN}$ is a Bayes-based graphical classifier with a strong independence assumption. It was introduced by Friedman et al (1997) to represent the relationships among variables (Song et al., 2012; Pham et al., 2016b). BN has a power classifier for assessing hazardous events 
(Liang et al., 2012). BN comprises two components: (1) directed acyclic graph (DAG) of the nodes in the $\mathrm{BN}$ classifiers that are corresponded to conditioning factors, and (2) a conditional distribution for each node determined by a conditional probability table (CPT). The CPT for each node can be calculated by Domain Knowledge (DK) using expert and Parameters Learned (PL) from sample datasets through machine learning or Bayesian estimation (Liang et al., 2012). The latter was used in this study. If $X_{r}$ represents a node in the $\mathrm{BN}$ classifier, then the joint probability distribution of a sinkhole in relation with a conditioning factor $X$ can be computed as:

$P_{B N}\left(X_{1}, X_{2}, \ldots, X_{n}\right)=\prod_{i=1}^{n} P_{B}\left(X_{1} \mid \prod_{X_{i}}\right)=\prod_{i=1}^{n} \theta_{X_{i} \mid \prod_{x_{i}}}$

(8)

where $\mathrm{X}=\left(\mathrm{X}_{1}, \mathrm{X}_{2}, \ldots, \mathrm{X}_{10}\right)$ denotes the sinkhole conditioning factors, and $\mathrm{P}_{\mathrm{B}}\left(\mathrm{X}_{1} \mid \prod_{\mathrm{X}_{\mathrm{i}}}\right)=\prod_{\mathrm{i}=1}^{10} \theta_{\mathrm{X}_{\mathrm{i}} \mid \prod_{\mathrm{x}_{\mathrm{i}}}}$ is a sinkhole joint probability distribution in relation with a conditioning factor $X_{i}$, and $n$ is the number of sinkhole conditioning factors.

\section{Logistic Regression (LR)}

LR is a multivariate statistical technique, in which the dependent variable should be binary or dichotomous, such as 0 and 1 , or presence and absence of an event, while independent variables (conditioning factors) can be continuous and categorical (Shirzadi et al., 2012; Shahabi et al., 2014; Chapi et al., 2017). It is a generalization of a linear model whereby relationships between the probability of sinkhole occurrence and the ten independent variables can be quantitatively computed as follows:

$P_{L R}=\frac{\mathrm{e}^{z}}{1+\mathrm{e}^{z}}$

(9)

$Z=\log \operatorname{it}(P)=\operatorname{Ln}\left(\frac{P}{1-P}\right)=c_{0}+a_{1} x_{1}, a_{2} x_{2}, \ldots, a_{n} x_{n}$

where $P_{L R}$ is the probability of sinkhole occurrence, $Z$ is the weighted linear combination of the independent variables, $c_{0}$ is the constant or intercept of model, $a_{\mathrm{i}}(\mathrm{i}=0,1,2, \ldots, \mathrm{n})$ are the coefficients, and $x_{i}=(\mathrm{i}=0,1,2, \ldots, \mathrm{n})$ are the independent variables (Chen et al., 2017b). 


\section{Bayesian Logistic Regression (BLR) classifier}

The BLR classifier is a combination of the NB classifier and the LR function. This classifier constructs the relationships between dependent (sinkhole and no-sinkhole) and independent (ten conditioning factors) variables (Chapi et al., 2017). The Bayesian framework is constructed in three steps; firstly, the prior probability (PP) is specified for each parameter; then the likelihood function (LF) is obtained for the dataset, and finally the posterior probability distribution (PPD) for the parameters is calculated (Avali et al., 2014). Let $\mathrm{X}=\left(\mathrm{x}_{1}, \mathrm{x}_{2}, \ldots, \mathrm{x}_{\mathrm{n}}\right)$ be the vector of the sinkhole conditioning factors of the training dataset $\mathrm{X}$, and $y=\left(y_{1}, y_{2}\right)$ the vector of the classifier dependent variables (sinkhole, no-sinkhole). PPD for a sample belonging to a specific class can be computed by the logistic function:

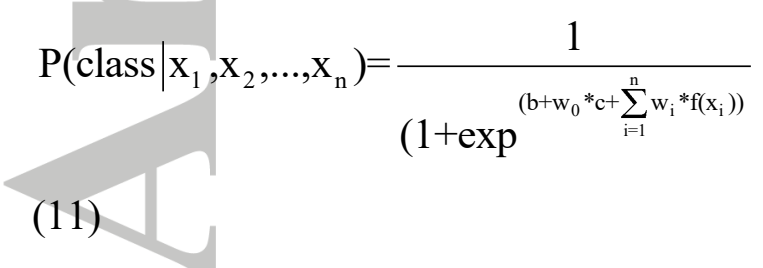

where $\mathrm{x}_{\mathrm{i}}$ denotes the sinkhole conditioning factors, $\mathrm{c}$ is the prior log odds ratio, which is obtained using $c=\log \frac{P(\text { class }=0)}{P(\text { class }=1)}, ' b$ ' is bias, weights $\mathrm{w}_{0}$ and $\mathrm{w}_{\mathrm{i}}$ are learned from the training dataset, and the $i^{\text {th }}$ attribute $\mathrm{x}_{\mathrm{i}}$ is utilized to obtain $\mathrm{f}\left(\mathrm{x}_{\mathrm{i}}\right)$ using $\log =\frac{P\left(x_{i} \mid \text { class }=0\right)}{P\left(x_{i} \mid \text { class }=1\right)}$ (for binary class outcome variables) (Figure 4).

\section{(Figure 4)}

\section{Accuracy assessment and comparison}

\section{The receiver operating characteristics curve}

The receiver operating characteristics curve (ROC) was used for the first time by the United States army to analyze the detection of radar signals related to Japanese aircrafts during Word War II (Ingleby, 1967). The aim of the receiver operating characteristic (ROC) method was to increasing the success rate in the detection of Japanese aircraft from radar signals. Subsequently, it has been used in psychophysics (Ingleby, 1967), medicine (Zweig \& Campbell, 1993; Pepe, 2003), and meteorology (Kharin \& Zwiers, 2003). However, the first application of the ROC curves in machine learning was carried out by Spackman (1989) for comparing and evaluating different classification algorithms (Spackman, 1989). The ROC curve is plotted in a two-dimensional graph with the sensitivity (true positives) in the $\mathrm{Y}$-axis 
and the specificity (false positives) in the X-axis, respectively. If it is based on the training dataset, the graph is named success rate curve (SRC) and if it is based on the validation dataset, it is designated as prediction rate curve (PRC) (Bradley, 1997).

The area under the ROC curve (AUROC) is a measure of the capability of the model to predict the spatial distribution of events (sinkhole) (Hong et al., 2017). It ranges between 0.5 (null prediction capability) and 1 (perfect model) (Shirzadi et al., 2017a). The AUROC can be classified into different predictive capability ranks as excellent $(0.9-1)$, very good (0.8$0.9)$, good (0.7-0.8), average (0.6-0.7) and poor (0.5-0.6) (Bui et al., 2017). The AUROC can be expressed as:

$$
\text { AUROC }=\frac{\left(\sum \mathrm{TP}+\sum \mathrm{TN}\right)}{(\mathrm{P}+\mathrm{N})}
$$

where TP is the number of sinkholes that are correctly classified, TN is the number of incorrectly classified sinkholes, $\mathrm{P}$ is the total number of sinkholes, and $\mathrm{N}$ is the total number of no-sinkhole pixels.

\section{Statistical index-based measures}

To further validate the performance of the models, some statistical indices including sensitivity, specificity, accuracy, Kappa index, root mean square error (RMSE), and mean absolute error (MAE) were used. These measures are obtained using the four possible consequences: true positive (TP), true negative (TN), false positive $(\mathrm{FP})$, and false negative (FN). TP and FP are defined as the proportion of sinkhole pixels correctly and incorrectly classified as sinkhole in the model, respectively. TN and FN are the proportion of the number of no-sinkhole pixels correctly and incorrectly classified as no-sinkhole, respectively (Pham et al., 2016a; Shirzadi et al., 2017a). These indices can be formulated as:

Precision $=\frac{\mathrm{TP}}{\mathrm{TP}+\mathrm{FP}}$

Sensitivity $=\frac{\mathrm{TP}}{\mathrm{TP}+\mathrm{FN}}$

Specificity $=\frac{\mathrm{TN}}{\mathrm{TN}+\mathrm{FP}}$ 


$$
\begin{aligned}
& \text { Accuracy }=\frac{\mathrm{TP}+\mathrm{TN}}{\mathrm{TP}+\mathrm{TN}+\mathrm{FP}+\mathrm{FN}} \\
& \text { Kappa index }(\mathrm{K})=\frac{\mathrm{P}_{\mathrm{C}}-\mathrm{P}_{\text {exp }}}{1-\mathrm{P}_{\text {exp }}} \\
& (17) \\
& \mathrm{P}_{\mathrm{C}}=(\mathrm{TP}+\mathrm{TN}) /(\mathrm{TP}+\mathrm{TN}+\mathrm{FN}+\mathrm{FP})
\end{aligned}
$$

$$
\mathrm{Pexp}=((\mathrm{TP}+\mathrm{FN})(\mathrm{TP}+\mathrm{FP})+(\mathrm{FP}+\mathrm{TN})(\mathrm{FN}+\mathrm{TN}) / \sqrt{(\mathrm{TP}+\mathrm{TN}+\mathrm{FN}+\mathrm{FP})})
$$

$$
\mathrm{RMSE}=\sqrt{\frac{1}{\mathrm{n}}} \sum_{\mathrm{i}=1}^{\mathrm{n}}\left(\mathrm{X}_{\text {est. }}-\mathrm{X}_{\text {obs. }}\right)^{2}
$$

$$
M A E=\frac{1}{N} \sum_{i=1}^{N}\left|X_{e s t}-X_{o b s}\right|
$$

(21)

where $\mathrm{n}$ is the total number of samples in the training or validation dataset; $\mathrm{X}_{\text {est. }}$ is the predicted values in the training or validation datasets; and $\mathrm{X}_{\text {obs. }}$ is the actual (output) values from the sinkhole susceptibility models.

\section{Non-parametric statistical assessment}

To evaluate significant differences among statistical treatments of two or more machine learning classifiers without recording their variances, parametric and non-parametric analyses can be applied. Although parametric statistical tests are utilized when data are normally distributed with equal variances, the non-parametric Freidman (Friedman, 1937) and Wilcoxon (Wilcoxon, 1945) tests are free from any statistical assumption. The null hypothesis is: there is no difference among the performances of sinkhole classifiers at a significant level of $\alpha=0.05$ (or $5 \%$ ). Consequently, based on the probability of a hypothesis (p-value), the null hypothesis is rejected or accepted if the p-value is true or false, respectively (Bui et al., 2016). If the p-value in the Freidman test is true in the models, the results of comparison among two or more models are not reliable. Hence, the Wilcoxon test is conducted to assess systematic pairwise differences among the sinkhole models using pvalue and z-value. Accordingly, the performance of the sinkhole susceptibility classifiers is 
significantly different (rejecting the null hypothesis) when the p-value is less than 0.05 and the z-value exceeds the critical values of $\mathrm{z}(-1.96$ and +1.96) (Bui et al., 2016).

\section{RESULTS AND DISCUSSION}

Sinkhole conditioning factor analysis

The prediction capability of the 10 sinkhole conditioning factors was evaluated using the IGR method in a 10-fold cross-validation on the training dataset (Table 3). The higher the IGR is, the higher the capability of the factor to predict the spatial distribution of new sinkholes will be. Results showed that bedrock lithology has the highest impact on sinkhole occurrence ( $\mathrm{IGR}=0.626$ ), followed by groundwater alkalinity ( $\mathrm{IGR}=0.37$ ), fault density $(\mathrm{IGR}=0.3$ ), distance to faults ( $I G R=0.28)$, penetration of deep wells into the karst aquifer $(\mathrm{IGR}=0.205)$, water level decline ( $\mathrm{IGR}=0.203$ ), groundwater exploitation ( $\mathrm{IGR}=0.119$ ), and distance to deep wells ( $I G R=0.101)$. IGR revealed that alluvial thickness and land-use, with $I G R=0$, have negligible predictive utility. Consequently, these conditioning factors were disregarded for the susceptibility modeling process. The obtained results are in agreement with Taheri et al. (2015), who reported that bedrock lithology reached the highest weight in comparison to other independent variables, using the analytical hierarchy process (AHP) method. Taheri et al. (2015) also indicated that the distance to deep wells (DDW) has the lowest AHP weight and has a limited utility for sinkhole modeling.

A critical and particularly challenging task of this work was the production of the data layer corresponding the bedrock lithology, since sinkholes mainly occur in areas where the bedrock is concealed by thick alluvium. The boundaries between the different lithological units in the areas covered by Quaternary deposits were delineated by interpolation, considering the contacts of the geological maps and the tectonic structures. Moreover, the distribution of sinkholes in the study area showed that they tend to form clusters and alignments, suggesting that faults may play a significant spatial control, as previously suggested by Taheri et al. (2015).

Initially, alluvial thickness and land-use were intuitively considered to be important factors for the development of the models. However, the computed IGR values revealed that these factors are not useful for modeling sinkhole susceptibility. It should be noted that these results are site-specific and may not be applicable in other regions.

\section{(Table 3)}




\section{Sinkhole susceptibility mapping}

After applying the BN, NB, LR and BLR statistical approaches, sinkhole susceptibility indices (SSIs) were estimated for each pixel in the different models. The SSIs are computed according to the probability distribution function (PDF) of each approach. For example, in the $\mathrm{BN}$ and NB methods, the PDFs are probability functions, whereas logistic functions are applied to calculate the SSIs indices in the LR and BLR approaches.

In order to facilitate the visualization of the susceptibility models, the indices were classified into five susceptibility classes by the natural break method: very low (VLS), low (LS), moderate (MS), high (HS), very high (VHS). Finally, four susceptibility maps were developed by the different statistical approaches (Figure 5). These maps consistently indicate that the central and southwestern parts of the study area, associated with major cartographic faults, significant water level decline and penetration of deep wells into the karst aquifer have the highest susceptibility to sinkhole occurrence.

\section{(Figure 5)}

\section{Model results and analysis}

Once the best conditioning factors and the parameters of the four different models were determined, their performances were evaluated using both the training (Table 4) and validation datasets (Table 3 ).

\section{(Table 4)}

According to the training dataset, the $\mathrm{BN}$ model has the best performance (goodness of fit) measured by RMSE, MAE and AUROC, and the NB model shows the best results in terms of sensitivity, specificity, accuracy, and Kappa indexes. According to the sensitivity criterion, the NB model (0.938) shows the best quality, with $93.8 \%$ of the sinkhole pixels correctly classified in the sinkhole classes, followed by BN (0.935), BLR (0.903) and LR (0.844). The NB model also has the highest specificity (0.938), with $93.8 \%$ of the no-sinkhole pixels correctly classified in the no-sinkhole class. The highest accuracy was achieved by the NB model (0.938), indicating that the probability of correctly classified pixels is $93.8 \%$, followed by the BN (0.922), BLR (0.891) and LR models (0.844).

The RMSE and MAE computed with the training dataset shows that the BN model has the highest fit (0.097 and 0.234), followed by the NB (0.107 and 0.271), BLR (0.109 and 0.3) and LR models (0.226 and 0.336). The NB model has the highest Kappa index (0.875) 
calculated with the training dataset, indicating an almost perfect agreement between estimation and observation, followed by the BN (0.843), BLR (0.781), and LR models $(0.681)$.

The ROC curves produced with the training dataset showed that the $\mathrm{BN}$ model has the highest AUROC (0.977), followed by the NB (0.954), LR (0.914) and BLR models (0.891). The prediction capability of the four models was evaluated using the validation dataset (Table 5). The four models showed excellent or very good prediction ability with the highest AUROC for the BN model (0.976), followed by the NB (0.899), BLR (0.867) and LR models (0.809). The Kappa index varies from 0.6 to 0.733 proving that all the models had almost perfect agreement with the validation dataset. The highest sensitivity corresponds to the NB (0.789), BN (0.789), and BLR models (0.789), indicating that $78.9 \%$ of the sinkhole pixels were correctly classified. The BN, NB and BLR models has the highest specificity index (1.0), with $100 \%$ of the no-sinkhole pixels correctly classified, followed by the LR model (0.909). The BN, NB and BLR models yield the highest accuracy (0.867), followed by the LR model (0.8). The BN model has the lowest RMSE and MAE (0.148 and 0.339), followed by the NB (0.151 and 0.362), BLR (0.153 and 0.365) and LR models (0.264 and 0.384).

Overall, the results indicate that the Bayes Net classifier (BN) approach allows generating a higher quality susceptibility model than the other statistical methods (NB, BLR and LR). The BN considers the uncertainty interdependence among conditioning factors and provides a semantic mode to check the missing data, decreasing noise and preventing over-fitting problems (Liang et al., 2012; Song et al., 2012). The obtained results are in agreement with Pham et al. (2016b), who compared five machine learning methods, namely Support Vector Machines (SVM), Logistic Regression (LR), Fisher's Linear Discriminant Analysis (FLDA), Bayesian Network (BN), and Naïve Bayes (NB) for the spatial prediction of landslides, concluding that the BN model outperformed the NB model.

\section{(Table 5)}

\section{Model validation and comparison}

The validity of the four susceptibility maps was quantitatively evaluated by the AUROC (Figure 6). The area under the success rate curve reaches the highest value for the BN model (0.909), followed by NB (0.888), LR (0.877) and BLR models (0.864) (Figure 6a). The highest area under the prediction rate curve was also achieved by $\mathrm{BN}$ (0.856), closely 
followed by NB (0.832), LR (0.811) and BLR (0.784). These values suggest that the BN model has the highest prediction capability.

\section{(Figure 6)}

Results indicated that all the models yield reliable predictions (Tables 5 and 6, and Figure 6). However, in order to determine whether they show statistically significant differences, the Freidman and Wilcoxon tests were applied at the 5\% significant level (Table 6). Results indicate that since P-value is $0.000(<0.05)$, the null hypothesis is rejected revealing that there are significant differences among the models.

(Table 6)

The Friedman test does not discriminate a model any significant difference. Therefore, the Wilcoxon test was used to check the statistical differences between any pair of sinkhole models (Table 7). The null hypothesis was rejected implying that the BN approach allows producing significantly different sinkhole susceptibility maps in the study area. Overall, the pairwise comparison showed that the performances of the four models are significantly different from each other, except for LR versus BLR, which showed equivalent performances.

(Table 7)

\section{CONCLUSIONS}

Sinkholes in the Hamadan typically occur in farmlands, pose a severe hazard to people and human structures and cause significant onsite and offsite land-degradation impacts, including disturbance of natural and artificial drainage systems and large amounts of soil loss. Effective management and mitigation of these detrimental consequences requires understanding the factors that govern their development and producing reliable predictions on their future distribution. As this work illustrates, identifying the most significant conditioning factors and testing the performance of different machine learning and statistical approaches (NB, BN, LR, and BLR) to predict the distribution of future sinkholes constitutes a valuable contribution for managing and mitigating the associated geoenvironmental problems.

The IGR values calculated for the ten conditioning factors considered in the analysis allowed the identification of : (1) the factors with greatest predictive capability, notably bedrock 
lithology; and (2) the factors with negligible statistical significance for sinkhole prediction (i.e., alluvial thickness and land use). The latter were disregarded in the susceptibility modeling process since they do not contribute to increase the prediction capability of the models. This step, which is rarely performed in susceptibility modeling, has several advantages, including: (1) the identification of the main factors that control the development of sinkholes, providing useful clues for hazard and risk mitigation, (2) contributes to reduce the effort/benefit ratio by disregarding particular factors in the data-collection and modeling process, and (3) may allow producing susceptibility models with higher prediction capability using a more limited amount of data.

The quantitative and independent evaluation of the susceptibility models developed with the different machine learning algorithms reveals that Bayes-based models (BN, NB, and BLR) provide more reliable predictions than statistical model (LR) measured by the AUROC. This is probably related to the fact that Bayes-based models are more adequate for analyzing complex phenomena governed by largely hidden factors such as sinkholes. The BN model produced the most reliable sinkhole susceptibility map.

The results obtained in the Hamadan region offer promising prospects in the field of sinkhole modeling and risk mitigation. Our findings can be applied by watershed managers, stakeholders, and land policy makers for managing and mitigating land degradation caused by sinkholes. However, additional work should be performed in order to assess wether these findings can be generalized and to improve the quality and usefulness of the predictions. It would be desirable to apply this methodology in other regions with different geological conditions and where sinkholes are controlled by other factors. It would be also advisable to assess the potential impact of improving the accuracy of the factors (e.g. spatial resolution) on the quality of the models. Moreover, transforming susceptibility models into hazard models that quantitatively estimate the probability of occurrence of new sinkholes in each portion of the territory would significantly increase the applicability of the models.

\section{Acknowledgment:}

We express our thanks to the Editor-in-Chief of the Land Degradation \& Development journal and four anonymous reviewers for their insightful comments and corrections. The work carried out by Francisco Gutiérrez is supported by project CGL2017-85045-P (Spanish Government). 


\section{References}

Avali VR, Cooper GF, Gopalakrishnan V. (2014). Application of Bayesian Logistic Regression to Mining Biomedical Data. Journal of the American Medical Informatics Association 21, 952968. DOI: 10.1136/amiajnl-2014-003170

Bowman RS. (1997). Aqueous environmental geochemistry. Eos, Transactions American Geophysical Union, 78, 586-586. DOI: 10.1029/97eo00355

Bradley AP. (1997). The use of the area under the ROC curve in the evaluation of machine learning algorithms. Pattern recognition, 30, 1145-1159. DOI: 10.1016/s0031-3203(96)00142-2

Bui DT, Khosravi K, Li S, Shahabi H, Panahi M, Singh V, Chapi K, Shirzadi A, Panahi S, Chen W. (2018a). New hybrids of Anfis with several optimization algorithms for flood susceptibility modeling. Water, 10, 1210-1231. DOI: 10.3390/w10091210

Bui DT, Nguyen QP, Hoang N-D, Klempe H. (2017). A novel fuzzy K-nearest neighbor inference model with differential evolution for spatial prediction of rainfall-induced shallow landslides in a tropical hilly area using GIS. Landslides, 14, 1-17. DOI: 10.1007/s10346-016-0708-4

Bui DT, Panahi M, Shahabi H, Singh VP, Shirzadi A, Chapi K, Khosravi K, Chen W, Panahi S, Li S. (2018b). Novel hybrid evolutionary algorithms for spatial prediction of floods. Scientific Reports, 8, 15364-1546. DOI: 10.1038/s41598-018-33755-7

Bui DT, Tuan TA, Klempe H, Pradhan B, Revhaug I. (2016). Spatial prediction models for shallow landslide hazards: a comparative assessment of the efficacy of support vector machines, artificial neural networks, kernel logistic regression, and logistic model tree. Landslides, 13, 361-378. DOI: 10.1007/s10346-015-0557-6

Chapi K, Singh VP, Shirzadi A, Shahabi H, Bui DT, Pham BT, Khosravi K. (2017). A novel hybrid artificial intelligence approach for flood susceptibility assessment. Environmental Modelling \& Software, 95, 229-245. DOI: 10.1016/j.envsoft.2017.06.012

Chen T, Niu R, Du B, Wang Y. (2015). Landslide spatial susceptibility mapping by using GIS and remote sensing techniques: a case study in Zigui County, the Three Georges reservoir, China. Environmental Earth Sciences, 73, 5571-5583. DOI: 10.1007/s12665-014-3811-7

Chen T, Niu R, Jia X. (2016). A comparison of information value and logistic regression models in landslide susceptibility mapping by using GIS. Environmental Earth Sciences, 75, 867-876. DOI: $10.1007 / \mathrm{s} 12665-016-5317-\mathrm{y}$

Chen T, Trinder JC, Niu R. (2017a). Object-oriented landslide mapping using ZY-3 satellite imagery, random forest and mathematical morphology, for the Three-Gorges Reservoir, China. Remote Sensing, 9, 333-349. DOI: 10.3390/rs9040333

Chen W, Li X, He H, Wang L. (2017). A review of fine-scale land use and land cover classification in open-pit mining areas by remote sensing techniques. Remote Sensing, 10, 1-19. DOI: $10.3390 / \mathrm{rs} 10010015$

Chen W, Li X, Wang Y, Chen G, Liu S. (2014). Forested landslide detection using LiDAR data and the random forest algorithm: A case study of the Three Gorges, China. Remote Sensing of Environment, 152, 291-301. DOI: 10.1016/j.rse.2014.07.004

Chen W, Pourghasemi HR, Zhao Z. (2017b). A GIS-based comparative study of Dempster-Shafer, logistic regression and artificial neural network models for landslide susceptibility mapping. Geocarto International, 32, 367-385. DOI: 10.1080/10106049.2016.1140824

Ciotoli G, Di Loreto E, Finoia M, Liperi L, Meloni F, Nisio S, Sericola A. (2016). Sinkhole susceptibility, Lazio Region, central Italy. Journal of Maps, 12, 287-294. DOI: 10.1080/17445647.2015.1014939

Doshi M. (2014). Correlation Based Feature Selection (Cfs) Technique To Predict Student Perfromance. International Journal of Computer Networks \& Communications, 6, 197-206. DOI: $10.5121 / \mathrm{ijcnc} .2014 .6315$

Filippi M, Bosák P. (2013). Proceedings of the $16^{\text {th }}$ International congress of speleology, Czech Speleological Society. Brno, 21-28 July 2013. 2, 453.

Ford D, Williams PD. (2013). Karst hydrogeology and geomorphology. New York: John Wiley \& Sons Ltd.

Friedman M. (1937). The use of ranks to avoid the assumption of normality implicit in the analysis of variance. Journal of the American Statistical Association, 32, 675-701. DOI: 10.2307/2279169 
Friedman N, Geiger D, Goldszmidt M. (1997). Bayesian network classifiers. Machine Learning, 29, 131-163. DOI: $10.7 / 1-412-43-7$

Galve J, Gutiérrez F, Lucha P, Bonachea J, Remondo J, Cendrero A, Gutiérrez M, Gimeno M, Pardo G, Sánchez J. (2009). Sinkholes in the salt-bearing evaporite karst of the Ebro River valley upstream of Zaragoza City (NE Spain): Geomorphological mapping and analysis as a basis for risk management. Geomorphology, 108, 145-158. DOI: 10.1016/j.geomorph.2008.12.018

Ghasemi A, Talbot CJ. (2006). A new tectonic scenario for the Sanandaj-Sirjan Zone (Iran). Journal of Asian Earth Sciences, 26, 683-693. DOI: 10.1016/j.jseaes.2005.01.003

Gunn J. (2004). Encyclopedia of caves and karst science. New York: Taylor \& Francis.

Gutiérrez F, Fabregat I, Roqué C, Carbonel D, Guerrero J, García-Hermoso F, Zarroca M, Linares R. (2016). Sinkholes and caves related to evaporite dissolution in a stratigraphically and structurally complex setting, Fluvia Valley, eastern Spanish Pyrenees. Geological, geomorphological and environmental implications. Geomorphology, 267, 76-97. DOI: 10.1016/j.geomorph.2016.05.018

Gutiérrez F, Parise M, De Waele J, Jourde H. (2014). A review on natural and human-induced geohazards and impacts in karst. Earth-Science Reviews, 138, 61-88. DOI: 10.1016/j.earscirev.2014.08.002

Heidari M, Khanlari G, Beydokhti AT, Momeni A. (2011). The formation of cover collapse sinkholes in North of Hamedan, Iran. Geomorphology, 132, 76-86. DOI: 10.1016/j.geomorph.2011.04.025

Hong H, Liu J, Zhu A-X, Shahabi H, Pham BT, Chen W, Pradhan B, Bui DT. (2017). A novel hybrid integration model using support vector machines and random subspace for weather-triggered landslide susceptibility assessment in the Wuning area (China). Environmental Earth Sciences, 76, 652-663. DOI: 10.1007/s12665-017-6981-2

Hyland SE. (2005). Analysis of sinkhole susceptibility and karst distribution in the northern Shenandoah Valley, Virginia: implications for low impact development (LID) site suitability models. Virginia Polytechnic Institute and State University.

Ingleby J. (1967). Book Review: Signal detection theory and psychophysics. by DM Green and JA Swets. New York: John Wiley \& Sons Ltd, 1966. Cloth. 104s. Journal of Sound Vibration, 5, 519-521. DOI: 10.1016/0022-460X(67)90197-6

Jafari R, Bakhshandehmehr L. (2016). Quantitative mapping and assessment of environmentally sensitive areas to desertification in central Iran. Land Degradation \& Development, 27, 108119. DOI: $10.1002 / 1 \mathrm{dr} .2227$

Kanevski M, Parkin R, Pozdnukhov A, Timonin V, Maignan M, Demyanov V, Canu S. (2004). Environmental data mining and modeling based on machine learning algorithms and geostatistics. Environmental Modelling \& Software, 19, 845-855. DOI: 10.1016/j.envsoft.2003.03.004

Karimi H, Taheri K. (2010). Hazards and mechanism of sinkholes on Kabudar Ahang and Famenin plains of Hamadan, Iran. Natural Hazards, 55, 481-499. DOI: 10.1007/s11069-010-9541-6

Khanlari G, Heidari M, Momeni AA, Ahmadi M, Beydokhti AT. (2012). The effect of groundwater overexploitation on land subsidence and sinkhole occurrences, western Iran. Quarterly Journal of Engineering Geology and Hydrogeology, 45, 447-456. DOI: 10.1144/qjegh2010-069

Kharin VV, Zwiers FW. (2003). On the ROC score of probability forecasts. Journal of Climate, 16, 4145-4150. DOI: 10.1175/1520-0442(2003)01<4145:otrsop>2.0.co;2

Liang W-j, Zhuang D-f, Jiang D, Pan J-j, Ren H-y. (2012). Assessment of debris flow hazards using a Bayesian Network. Geomorphology, 171, 94-100. DOI: 10.1016/j.geomorph.2012.05.008

Minaei M, Shafizadeh-Moghadam H, Tayyebi A. (2018). Spatiotemporal nexus between the pattern of land degradation and land cover dynamics in Iran. Land Degradation \& Development, 29, 2854-2863. DOI: 10.1002/ldr.3007

Naghibi SA, Pourghasemi HR, Abbaspour K. (2017). A comparison between ten advanced and soft computing models for groundwater qanat potential assessment in Iran using R and GIS. Theoretical and Applied Climatology, 131, 967 to 984. DOI: 10.1007/s00704-016-2022-4

Newton J. (1984). Natural and induced sinkhole development in the eastern United States. In Proceedings of the Third International Symposium on Land Subsidence, International Association of Hydrological Sciences, Wallingford, UK; 549-564. 
Papadopoulou-Vrynioti K, Bathrellos GD, Skilodimou HD, Kaviris G, Makropoulos K. (2013). Karst collapse susceptibility mapping considering peak ground acceleration in a rapidly growing urban area. Engineering Geology, 158. DOI: 10.1016/j.enggeo.2013.02.009 77-88

Parise M. (2013). Recognition of instability features in artificial cavities. In: Filippi M, Bosak P (eds) Proceedings of the $16^{\text {th }}$ International Congress of Speleology; Brno, 21-28 July 2013, 2, 224 229.

Pepe MS. (2003). The statistical evaluation of medical tests for classification and prediction. Oxford Statistical Science Series, UK

Pham BT, Bui D, Prakash I, Dholakia M. (2016a). Evaluation of predictive ability of support vector machines and naive Bayes trees methods for spatial prediction of landslides in Uttarakhand state (India) using GIS. Journal of Geomatics, 10, 71-79. DOI: oi.org/10.18165/ig/v6i1.08

Pham BT, Bui DT, Pourghasemi HR, Indra P, Dholakia M. (2017). Landslide susceptibility assesssment in the Uttarakhand area (India) using GIS: a comparison study of prediction capability of naïve bayes, multilayer perceptron neural networks, and functional trees methods. Theoretical and Applied Climatology, 128, 255-273. DOI: 10.1007/s00704-015-1702-9

Pham BT, Pradhan B, Bui DT, Prakash I, Dholakia M. (2016b). A comparative study of different machine learning methods for landslide susceptibility assessment: a case study of Uttarakhand area (India). Environmental Modelling \& Software, 84, 240-250. DOI: 10.1016/j.envsoft.2016.07.005

Pradhan B. (2013). A comparative study on the predictive ability of the decision tree, support vector machine and neuro-fuzzy models in landslide susceptibility mapping using GIS. Computers \& Geosciences, 51, 350-365. DOI: 10.1016/j.cageo.2012.08.023

Pradhan B, Abokharima MH, Jebur MN, Tehrany MS. (2014). Land subsidence susceptibility mapping at Kinta Valley (Malaysia) using the evidential belief function model in GIS. Natural Hazards, 73, 1019-1042. DOI: 10.1007/s11069-014-1128-1

Pradhan B, Oh H-J, Buchroithner M. (2010). Weights-of-evidence model applied to landslide susceptibility mapping in a tropical hilly area. Geomatics, Natural Hazards and Risk, 1, 199223. DOI.org/10.1080/19475705.2010.498151

Quinlan JR. (1996). Bagging, boosting, and C4. 5. In AAAI/IAAI, 1; 725-730.

Sabziparvar A. (2003). The analysis of aridity and meteorological drought indices in west of Iran. $B u$ Ali Sina University, Iran.

Salvati R, Sasowsky ID. (2002). Development of collapse sinkholes in areas of groundwater discharge. Journal of Hydrology, 264, 1-11. DOI: 10.1016/s0022-1694(02)00062-8

Shafizadeh-Moghadam H, Valavi R, Shahabi H, Chapi K, Shirzadi A. (2018). Novel forecasting approaches using combination of machine learning and statistical models for flood susceptibility mapping. Journal of Environmental Management, 217, 1-11. DOI: 10.1016/j.jenvman.2018.03.089

Shahabi H, Khezri S, Ahmad BB, Hashim M. (2014). Landslide susceptibility mapping at central Zab basin, Iran: a comparison between analytical hierarchy process, frequency ratio and logistic regression models. Catena, 115, 55-70. DOI: 10.1016/j.catena.2013.11.014

Shirzadi A, Bui DT, Pham BT, Solaimani K, Chapi K, Kavian A, Shahabi H, Revhaug I. (2017a). Shallow landslide susceptibility assessment using a novel hybrid intelligence approach. Environmental Earth Sciences, 76, 60-79. DOI: 10.1007/s12665-016-6374-y

Shirzadi A, Saro L, Joo OH, Chapi K. (2012). A GIS-based logistic regression model in rock-fall susceptibility mapping along a mountainous road: Salavat Abad case study, Kurdistan, Iran. Natural Hazards, 64, 1639-1656. DOI: 10.1007/s11069-012-0321-3

Shirzadi A, Shahabi H, Chapi K, Bui DT, Pham BT, Shahedi K, Ahmad BB. (2017b). A comparative study between popular statistical and machine learning methods for simulating volume of landslides. Catena, 157, 213-226. DOI: 10.1016/j.catena.2017.05.016

Song Y, Gong J, Gao S, Wang D, Cui T, Li Y, Wei B. (2012). Susceptibility assessment of earthquake-induced landslides using Bayesian network: a case study in Beichuan, China. Computers \& Geosciences, 42, 189-199. DOI: 10.1016/j.cageo.2011.09.011

Soni J, Ansari U, Sharma D, Soni S. (2011). Predictive data mining for medical diagnosis: An overview of heart disease prediction. International Journal of Computer Applications, 17, 43 48. DOI: $10.5120 / 2237-2860$ 
Spackman KA. (1989). Signal detection theory: Valuable tools for evaluating inductive learning. In Proceedings of the sixth international workshop on Machine learning. Cornell University, Ithaca, New York (USA); 160-163. DOI: 10.1016/b978-1-55860-036-2.50047-3

Symeonakis E, Karathanasis N, Koukoulas S, Panagopoulos G. (2016). Monitoring sensitivity to land degradation and desertification with the environmentally sensitive area index: The case of Lesvos Island. Land Degradation \& Development, 27, 1562-1573. DOI: 10.1002/ldr.2285

Taheri K, Gutiérrez F, Mohseni H, Raeisi E, Taheri M. (2015). Sinkhole susceptibility mapping using the analytical hierarchy process (AHP) and magnitude-frequency relationships: a case study in Hamadan Province, Iran. Geomorphology, 234, 64-79. DOI: 10.1016/j.geomorph.2015.01.005

Taheri K, Taheri M, Parise M. (2016). Impact of intensive groundwater exploitation on an unprotected covered karst aquifer: a case study in Kermanshah Province, western Iran. Environmental Earth Sciences, 75, 1221. DOI: 10.1007/s12665-016-5995-5

Tien Bui D, Pradhan B, Lofman O, Revhaug I. (2012). Landslide susceptibility assessment in vietnam

using support vector machines, decision tree, and naive bayes models. Mathematical Problems in Engineering, 2012, 1-26. DOI: 10.1155/2012/974638

Tien Bui D, Shahabi H, Shirzadi A, Chapi K, Pradhan B, Chen W, Khosravi K, Panahi M, Bin Ahmad B, Saro L. (2018). Land subsidence susceptibility mapping in South Korea using machine learning algorithms. Sensors, 18, 2464. DOI: 10.3390/s18082464

Vattano M, Parise M, Lollino P, Bonamini M, Maggio D, Madonia G. (2013). Examples of anthropogenic sinkholes in Sicily and comparison with similar phenomena in southern Italy. In Proceedings of the $13^{\text {th }}$ Multidisciplinary Conference on Sinkholes and the Engineering and Environmental Impacts of Karst. National Cave and Karst Research Institute: Carlsbad (New Mexico, USA): NCKRI Symposium 2; 263-271.

Wilcoxon F. (1945). Individual comparisons by ranking methods. Biometrics Bulletin, 1, 80-83. DOI: $10.2307 / 3001968$

Yilmaz I. (2007). GIS based susceptibility mapping of karst depression in gypsum: a case study from Sivas Basin (Turkey). Engineering Geology, 90, 89-103. DOI: 10.1016/j.enggeo.2006.12.004

Yilmaz I, Marschalko M, Bednarik M. (2013). An assessment on the use of bivariate, multivariate and soft computing techniques for collapse susceptibility in GIS environ. Journal of Earth System Science, 122, 371-388. DOI: 10.1007/s12040-013-0281-3

Youssef AM, Al-Harbi HM, Gutiérrez F, Zabramwi YA, Bulkhi AB, Zahrani SA, Bahamil AM, Zahrani AJ, Otaibi ZA, El-Haddad BA. (2016). Natural and human-induced sinkhole hazards in Saudi Arabia: distribution, investigation, causes and impacts. Hydrogeology Journal, 24, 625644. DOI: $10.1007 / \mathrm{s} 10040-015-1336-0$

Zweig MH, Campbell G. (1993). Receiver-operating characteristic (ROC) plots: a fundamental evaluation tool in clinical medicine. Clinical Chemistry, 39, 561-577. DOI: 10.2172/1093414 
Table 1 Sinkhole inventory over the study area

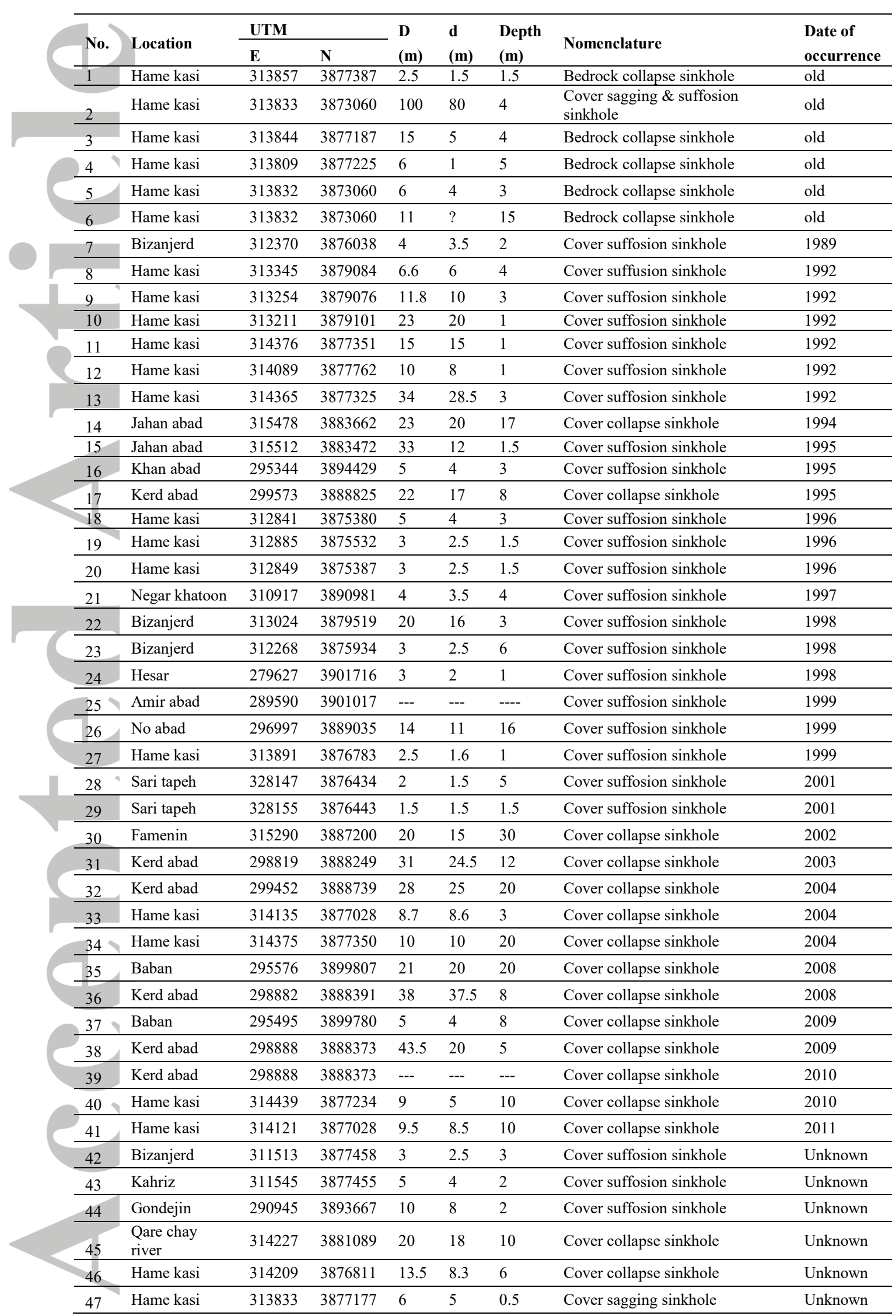

D: major axial length (m), d: minor axial length (m), asterisks denote sinkholes of doubtful origin, which may be related to karst voids or anthropogenic cavities, like old qanats or abandoned water wells. 
Table 2 Factors used in sinkhole susceptibility assessment and data sources

\begin{tabular}{|c|c|c|c|}
\hline Variable & Layer & Source & Scale/ Resolution \\
\hline Sinkhole location & SL & Field survey & $5 \mathrm{~m} \times 5 \mathrm{~m}$ \\
\hline $\begin{array}{l}\text { Distance to faults } \\
\text { Fault density }\end{array}$ & $\begin{array}{l}\text { DF } \\
\text { FD }\end{array}$ & $\begin{array}{l}\text { Geological map of } \\
\text { Iran }\end{array}$ & $1: 100,000 / 30 \mathrm{~m}$ \\
\hline Water Level Decline & WLD & $\begin{array}{l}\text { Calculated from } \\
\text { HWRC piezometric } \\
\text { data }\end{array}$ & $30 \mathrm{~m}$ \\
\hline $\begin{array}{l}\text { Groundwater } \\
\text { Exploitation }\end{array}$ & GE & $\begin{array}{l}\text { HWRC groundwater } \\
\text { data base }\end{array}$ & $30 \mathrm{~m}$ \\
\hline $\begin{array}{l}\text { Penetration of deep } \\
\text { wells into karst } \\
\text { aquifer }\end{array}$ & PKA & $\begin{array}{l}\text { Extracted from } \\
\text { HWRC dossiers of } \\
\text { the over } 3000 \text { public } \\
\text { production wells }\end{array}$ & $30 \mathrm{~m}$ \\
\hline $\begin{array}{l}\text { Distance to deep } \\
\text { wells }\end{array}$ & DDW & $\begin{array}{l}\text { HWRC wells data } \\
\text { base }\end{array}$ & $30 \mathrm{~m}$ \\
\hline $\begin{array}{l}\text { Groundwater } \\
\text { alkalinity }\end{array}$ & GA & $\begin{array}{l}\text { Gathered Data } \\
\text { available and } \\
\text { obtained by authors }\end{array}$ & $30 \mathrm{~m}$ \\
\hline Bedrock lithology & BL & $\begin{array}{l}\text { Data from around } \\
330 \text { exploration and } \\
\text { production wells } \\
\text { processed by the } \\
\text { authors }\end{array}$ & $30 \mathrm{~m}$ \\
\hline Alluvium thickness & AT & Geophysical map & $30 \mathrm{~m}$ \\
\hline d & $\mathbf{L U}$ & $\begin{array}{c}\text { OLI-sensor images of } \\
\text { satellite Landsat } 8\end{array}$ & $30 \mathrm{~m}$ \\
\hline
\end{tabular}


Table 3 Factor selection based on information gain ratio (IGR) in this study

\begin{tabular}{cccc}
\hline Row & Factors & IGR \\
\cline { 2 - 4 } & Lithology & 0.626 \\
2 & GA & 0.375 \\
3 & FD & 0.308 \\
4 & DF & 0.283 \\
5 & PKA & 0.205 \\
6 & WLD & 0.203 \\
7 & GE & 0.119 \\
8 & DDW & 0.101 \\
9 & AT & 0 \\
10 & Land use & 0 \\
\hline
\end{tabular}


Table 4 Parameters of machine learning algorithms applied in this study

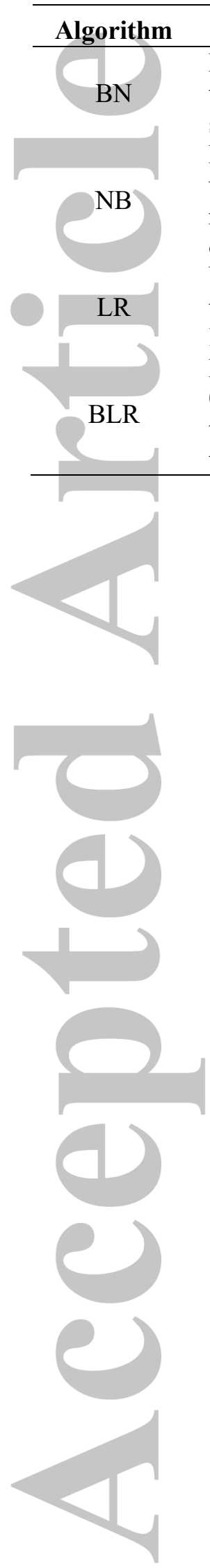

\section{Parameters}

Debug: false; Estimator: Simple estimator for finding the conditional probability tables of the Bayes Network; Search algorithm: K2 for searching network structures; Use ADTree: false.

Debug: false; display Model In Old Format (use old format for model output): false; use Kernel Estimator (use a kernel estimator for numeric attributes rather than a normal distribution): false; use Supervised Discretization (use supervised discretization to convert numeric attributes to nominal ones): false.

Use Quasi-Newton Method to search for the optimized values of the $\mathrm{m}^{*}(\mathrm{k}-1)$ variables; Maximum number of iterations to perform, -1 ; the Ridge value in the loglikelihood, 1.0E-8.

Hyper parameter value range, R:0.01-316,3.16; Specific hyper parameter value, 0.27; The maximum number of iterations to perform, 1000; The number of folds in the internal cross-validation or pruning, 2; The random number seed, 1; the threshold for classification, 0.5 . 
Table 5 Model performance on the training $(\mathrm{T})$ and validation $(\mathrm{V})$ datasets

\begin{tabular}{lccccccccc}
\hline Parameters & \multicolumn{2}{c}{ BN } & \multicolumn{2}{c}{ NB } & \multicolumn{3}{c}{ LR } & \multicolumn{2}{c}{ BLR } \\
\cline { 2 - 9 } & $\mathbf{T}$ & $\mathbf{V}$ & $\mathbf{T}$ & $\mathbf{V}$ & $\mathbf{T}$ & $\mathbf{V}$ & $\mathbf{T}$ & $\mathbf{V}$ \\
\hline TP & 29 & 15 & 30 & 15 & 27 & 14 & 28 & 15 \\
TN & 30 & 11 & 30 & 11 & 27 & 10 & 29 & 11 \\
FP & 3 & 0 & 2 & 0 & 5 & 1 & 4 & 0 \\
FN & 2 & 4 & 2 & 4 & 5 & 5 & 3 & 4 \\
Sensitivity & 0.935 & 0.789 & 0.938 & 0.789 & 0.844 & 0.737 & 0.903 & 0.789 \\
Specificity & 0.909 & 1.000 & 0.938 & 1.000 & 0.844 & 0.909 & 0.879 & 1.000 \\
Accuracy & 0.922 & 0.867 & 0.938 & 0.867 & 0.844 & 0.800 & 0.891 & 0.867 \\
RMSE & 0.097 & 0.148 & 0.107 & 0.151 & 0.226 & 0.246 & 0.109 & 0.153 \\
MAE & 0.234 & 0.339 & 0.271 & 0.362 & 0.336 & 0.384 & 0.300 & 0.365 \\
Kappa & 0.843 & 0.733 & 0.875 & 0.733 & 0.687 & 0.600 & 0.781 & 0.733 \\
AUROC & 0.977 & 0.976 & 0.954 & 0.899 & 0.914 & 0.809 & 0.891 & 0.867 \\
\hline
\end{tabular}


Table 6 Average ranking of the four sinkhole susceptibility models for the study area using the Friedman's test

\begin{tabular}{cccccc}
\multicolumn{5}{c}{ Using the Friedman's test } \\
\cline { 2 - 6 } & No & Sinkhole models & Mean ranks & $\boldsymbol{\chi}^{\mathbf{2}}$ & Sig. \\
\cline { 2 - 6 } & BN & 1.79 & & \\
2 & NB & 1.49 & 124.064 & 0.000 \\
3 & LR & 3.26 & & \\
\hline 4 & BLR & 3.46 & &
\end{tabular}
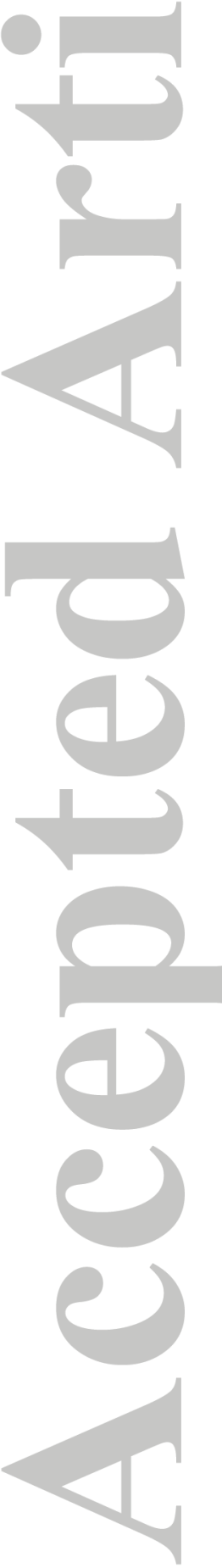
Table 7 Performance of the sinkhole susceptibility models using Wilcoxon signed-rank test

\begin{tabular}{ccccccc}
\multicolumn{7}{c}{ (two-tailed) } \\
\hline NO & $\begin{array}{c}\text { Pair wise } \\
\text { comparison }\end{array}$ & $\begin{array}{c}\text { Number of positive } \\
\text { differences }\end{array}$ & $\begin{array}{c}\text { Number of } \\
\text { negative } \\
\text { differences }\end{array}$ & z-value & p-value & Significance \\
\hline 1 & BN vs. NB & 20 & 4 & -2.676 & 0.007 & Yes \\
2 & BN vs. LR & 58 & 5 & -6.353 & 0.000 & Yes \\
3 & BN vs. BLR & 59 & 5 & -6.728 & 0.000 & Yes \\
4 & NB vs. LR & 61 & 3 & -6.487 & 0.000 & Yes \\
5 & NB vs. BLR & 59 & 4 & -6.791 & 0.000 & Yes \\
6 & LR vs. BLR & 39 & 25 & -0.976 & $\mathbf{0 . 3 2 9}$ & NO \\
\hline
\end{tabular}

(The standard $p$ value is 0.05 )
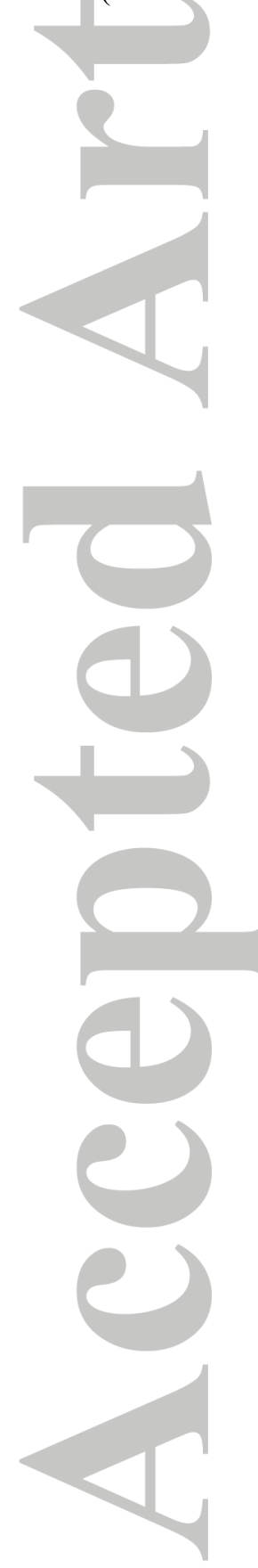
Figure 1 a) Geographic location of the study area in northwestern Iran; b) location of the Kabudar Ahang and Razan-Qahavand subcatchments (KRQ) in northern Hamadan Province; c) sketch of the KRQ of the Hoz-e-soltan of Qom watershed showing the distribution of alluvial aquifers and the sinkholes used for the development and validation of the susceptibility models; d) cover-collapse sinkhole at Jahan Abad; e) bedrock and covercollapse sinkhole at Hame kesi; f and g) cover collapse sinkholes in Hame kasi.

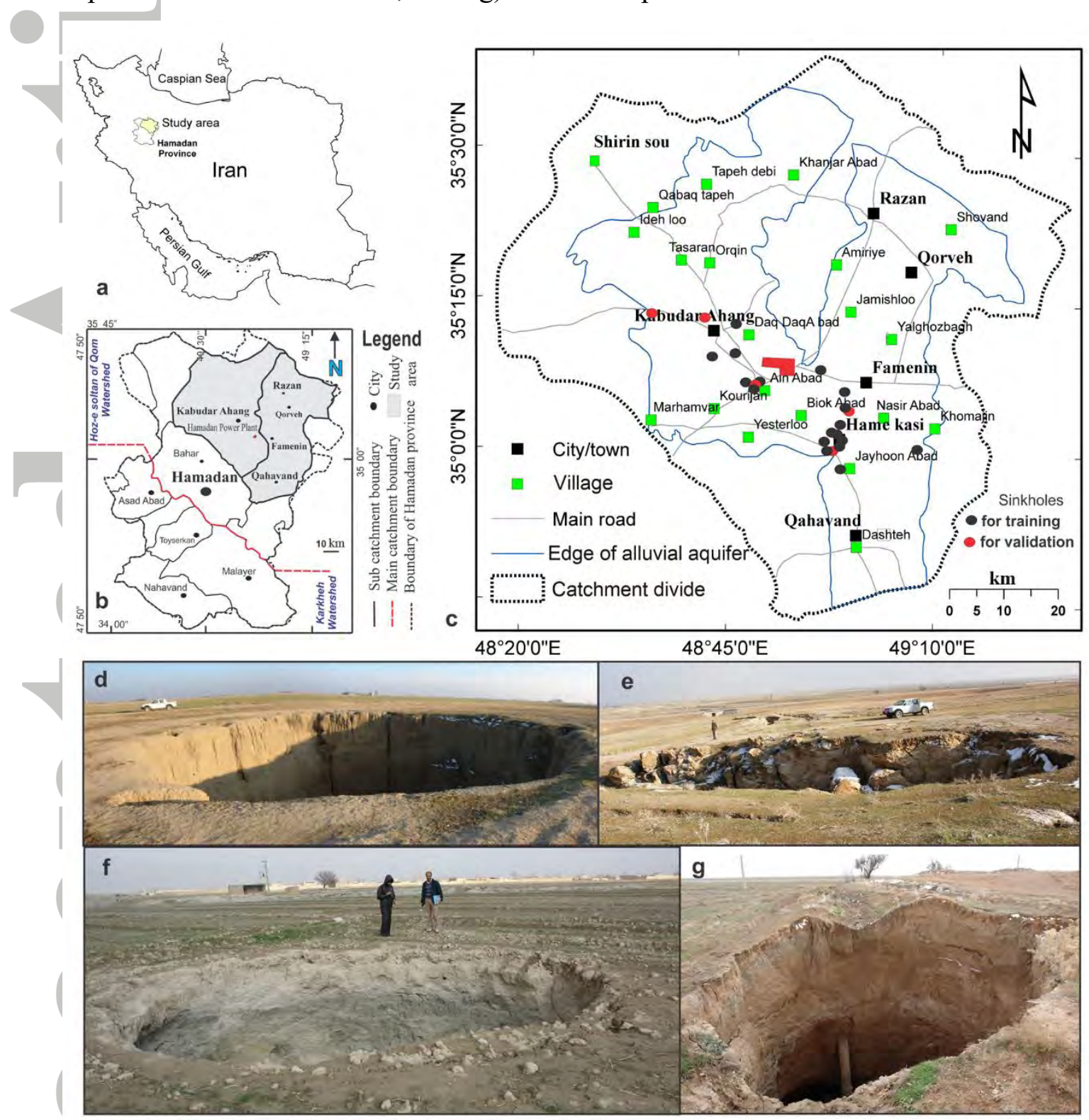


Figure 2 Geological map of the KRQ showing sample locations

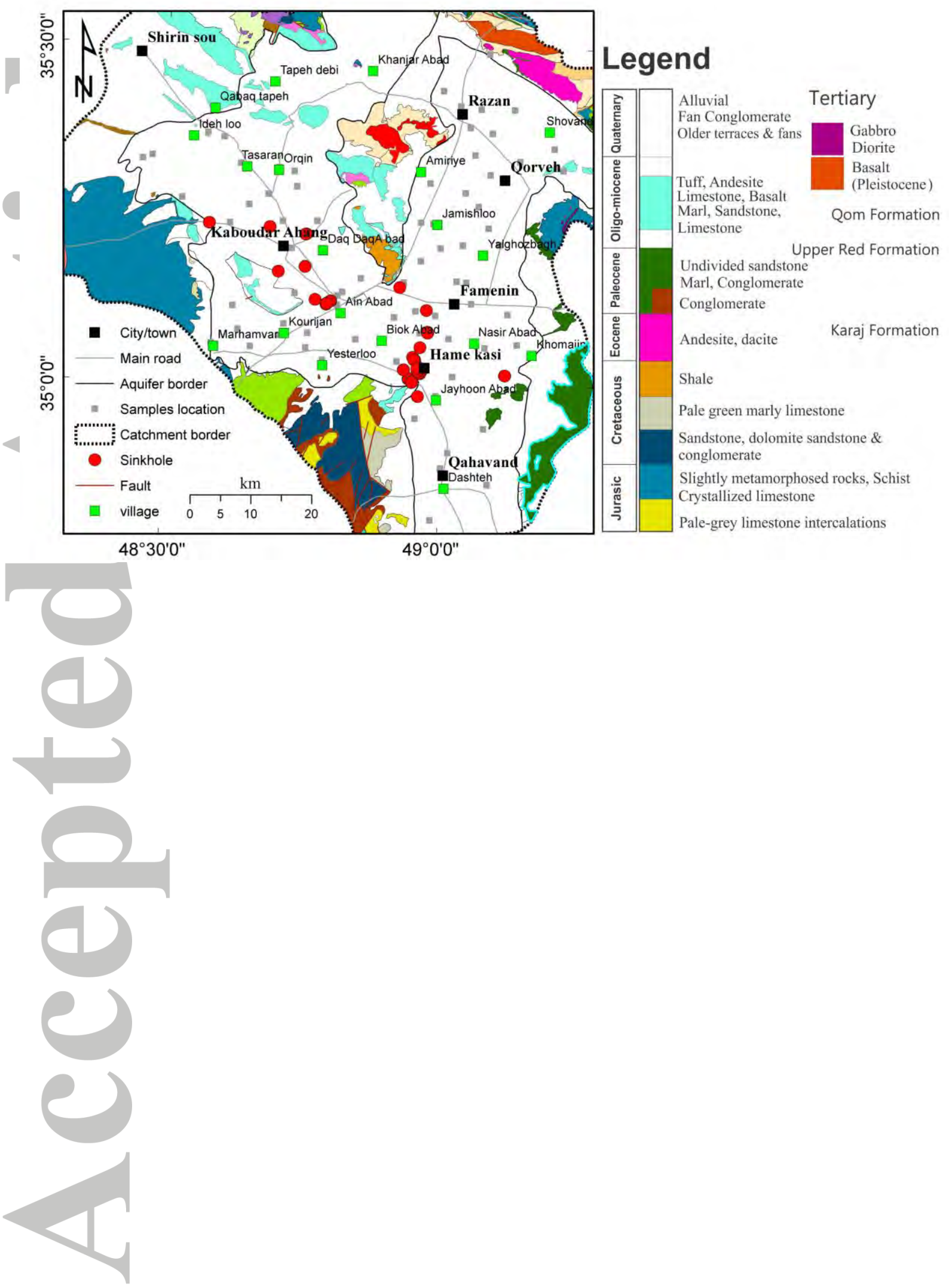


Figure 3 Thematic maps of the analyzed conditioning factors that affect sinkhole occurrence in the study area: a) water level decline (WLD); b) groundwater exploitation (GE); c) penetration of deep wells into the karst aquifer (PKA); d) distance to deep wells (DDW); e) groundwater alkalinity (GA); f) bedrock lithology (BL); g) alluvium thickness (AT); h) distance to faults (DF); i) fault density (FD); and j) land use (LU).
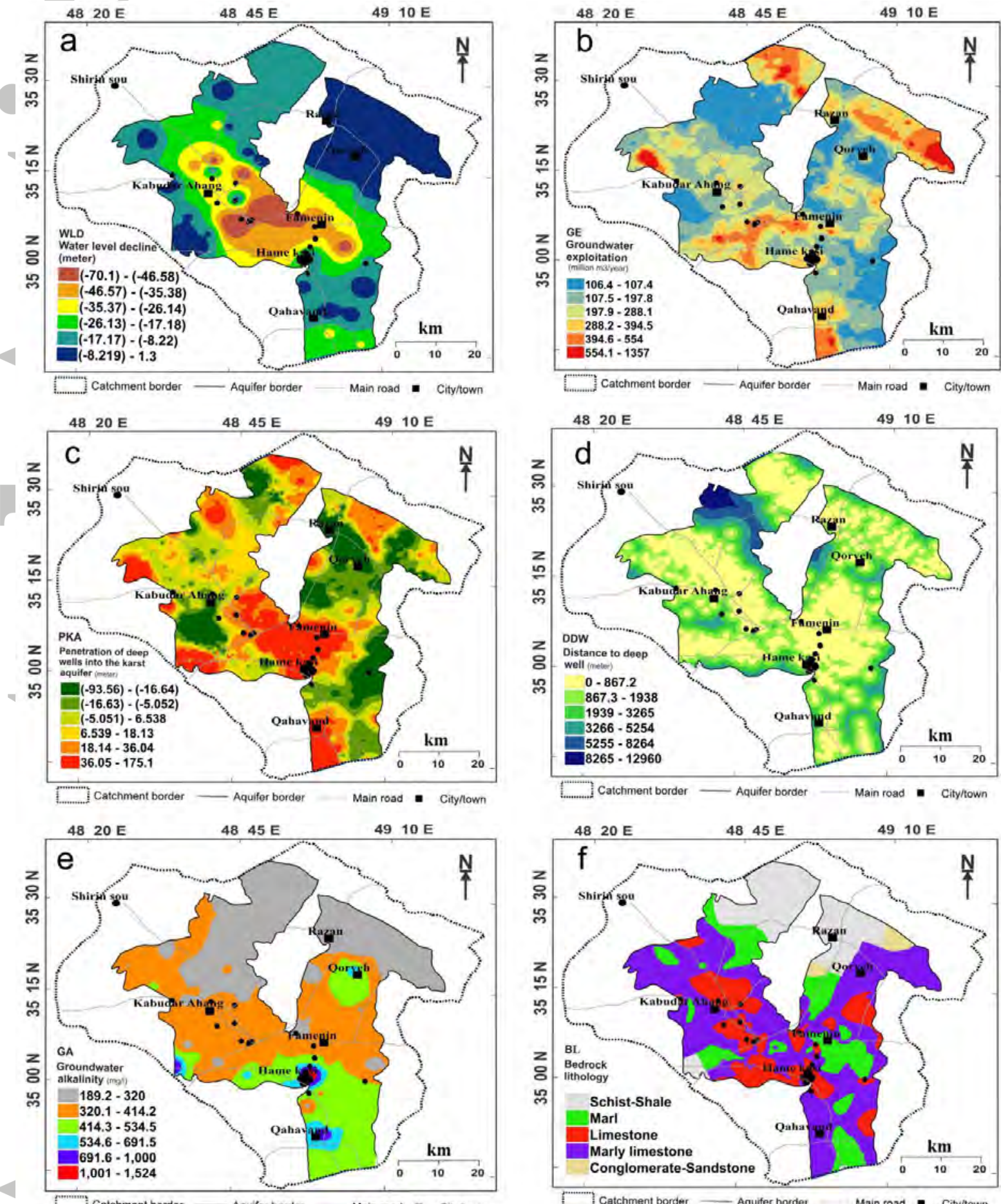

Catchment border —_ Aquifer border __ Main road a Cityfown

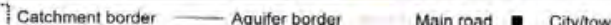



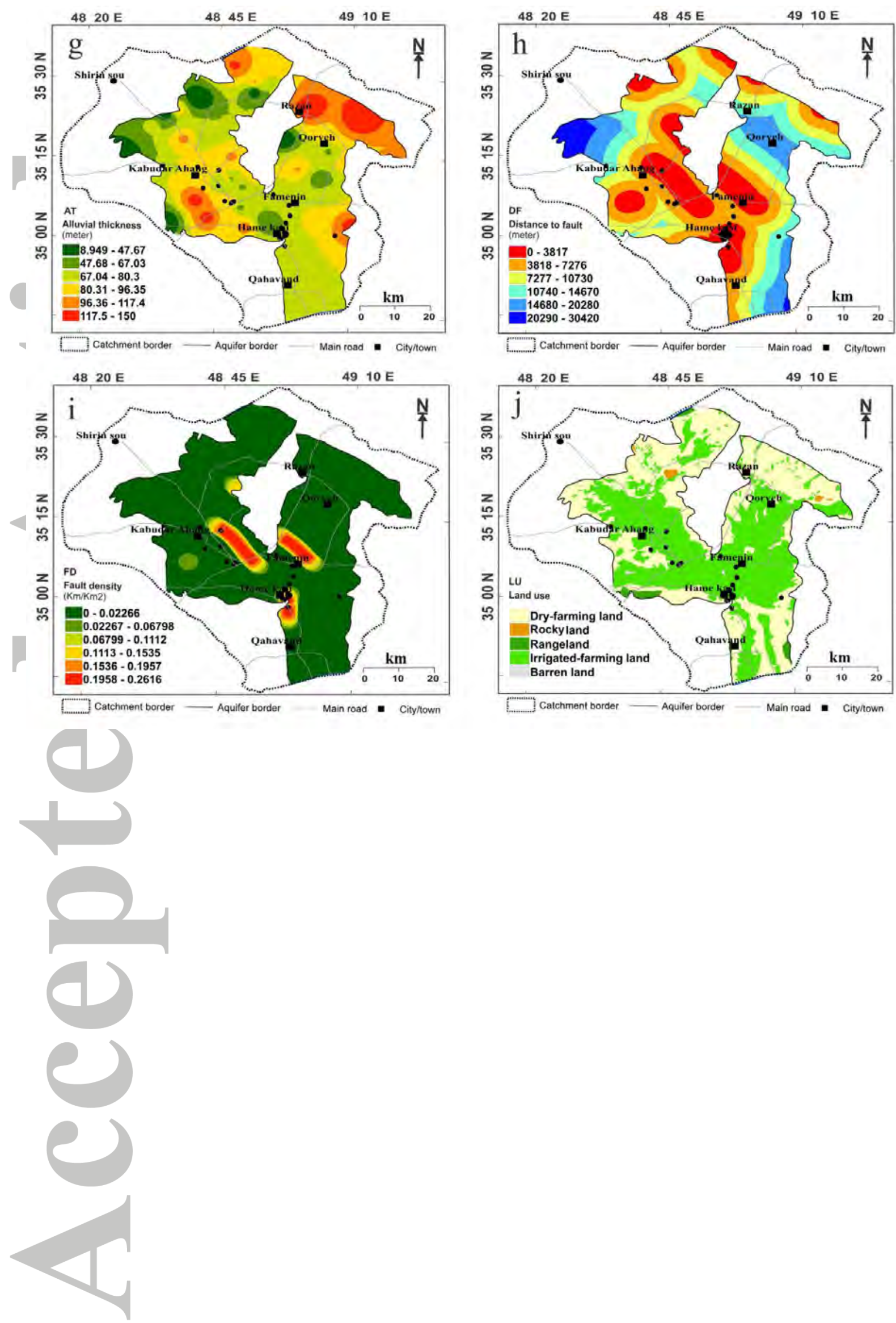

This article is protected by copyright. All rights reserved. 
Figure 4 Flowchart of machine learning algorithms for sinkhole susceptibility mapping
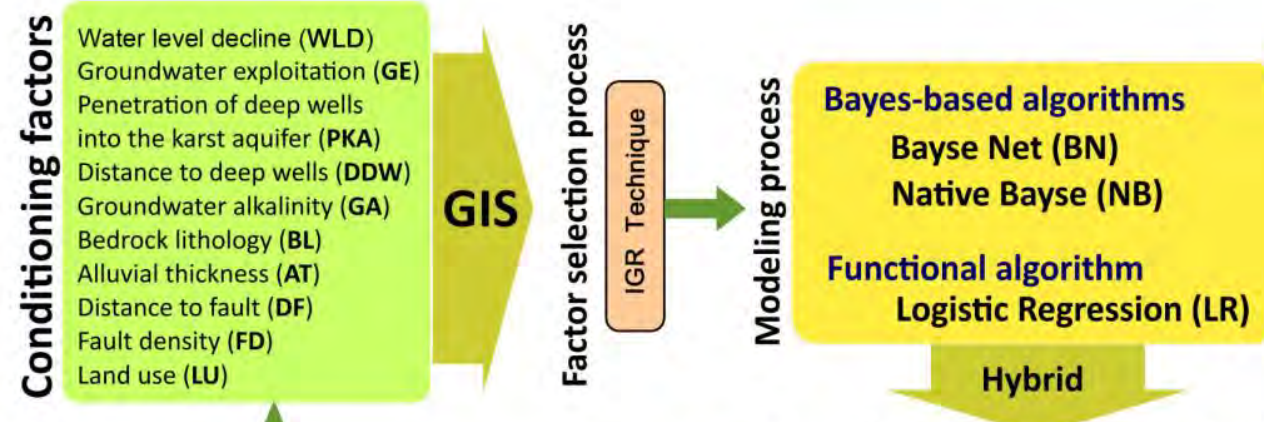

Bayesian Logistic Regression (BLR)
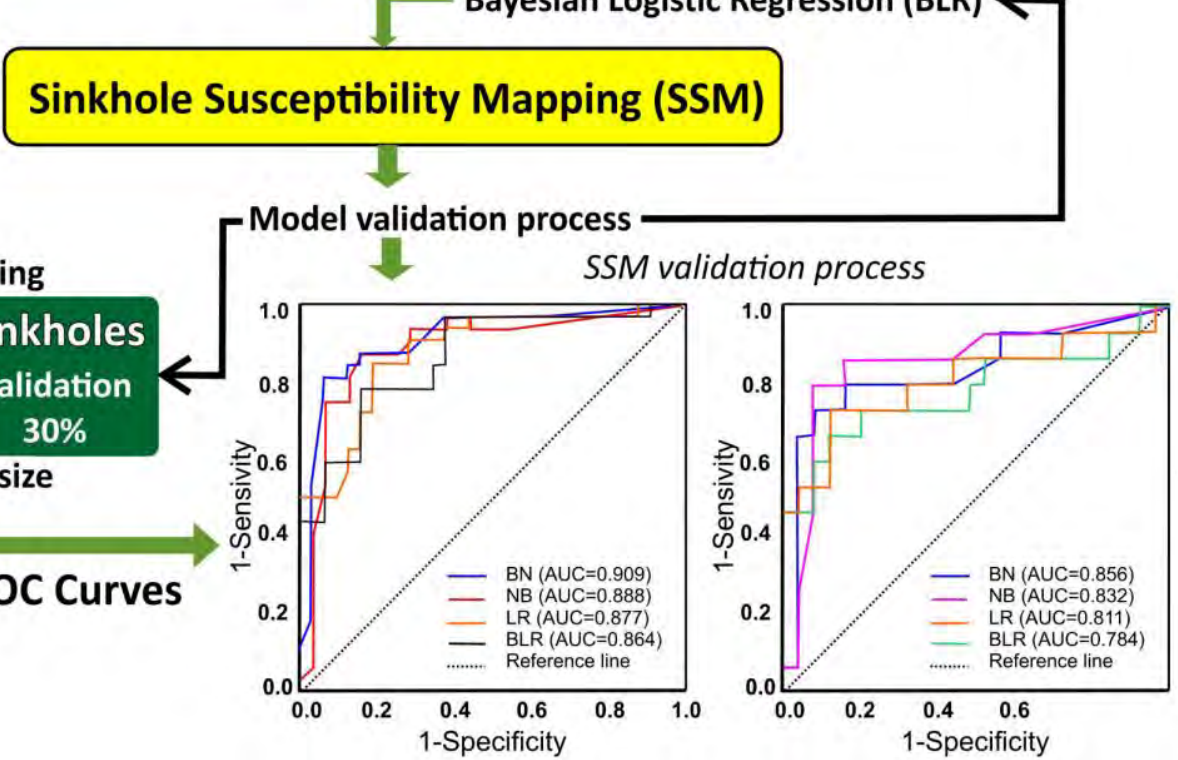

This article is protected by copyright. All rights reserved. 
Figure 5 Sinkhole susceptibility maps developed using the different statistical approaches.
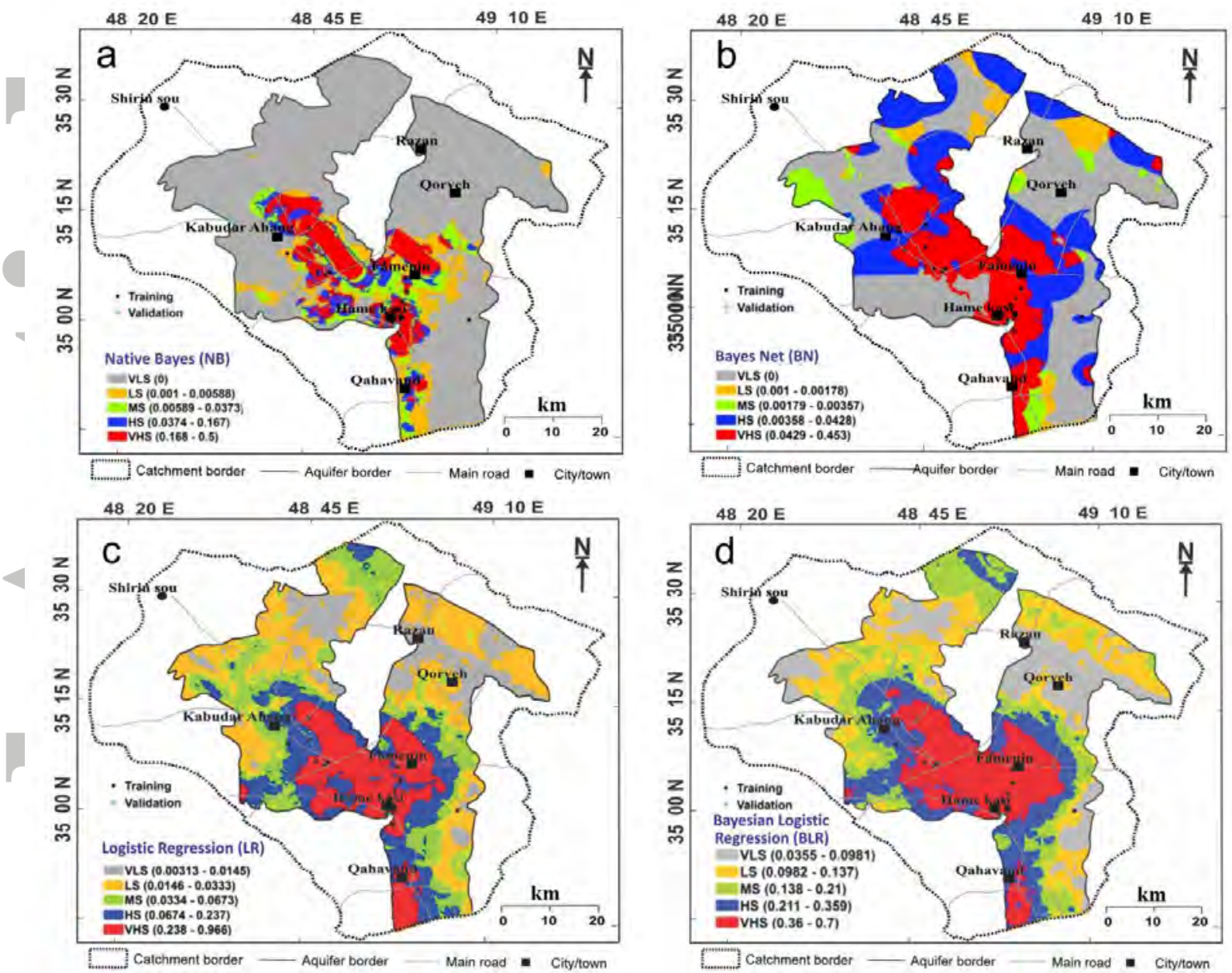
Figure 6 AUROC curve and of the models using the training dataset (left) and validation dataset (right)
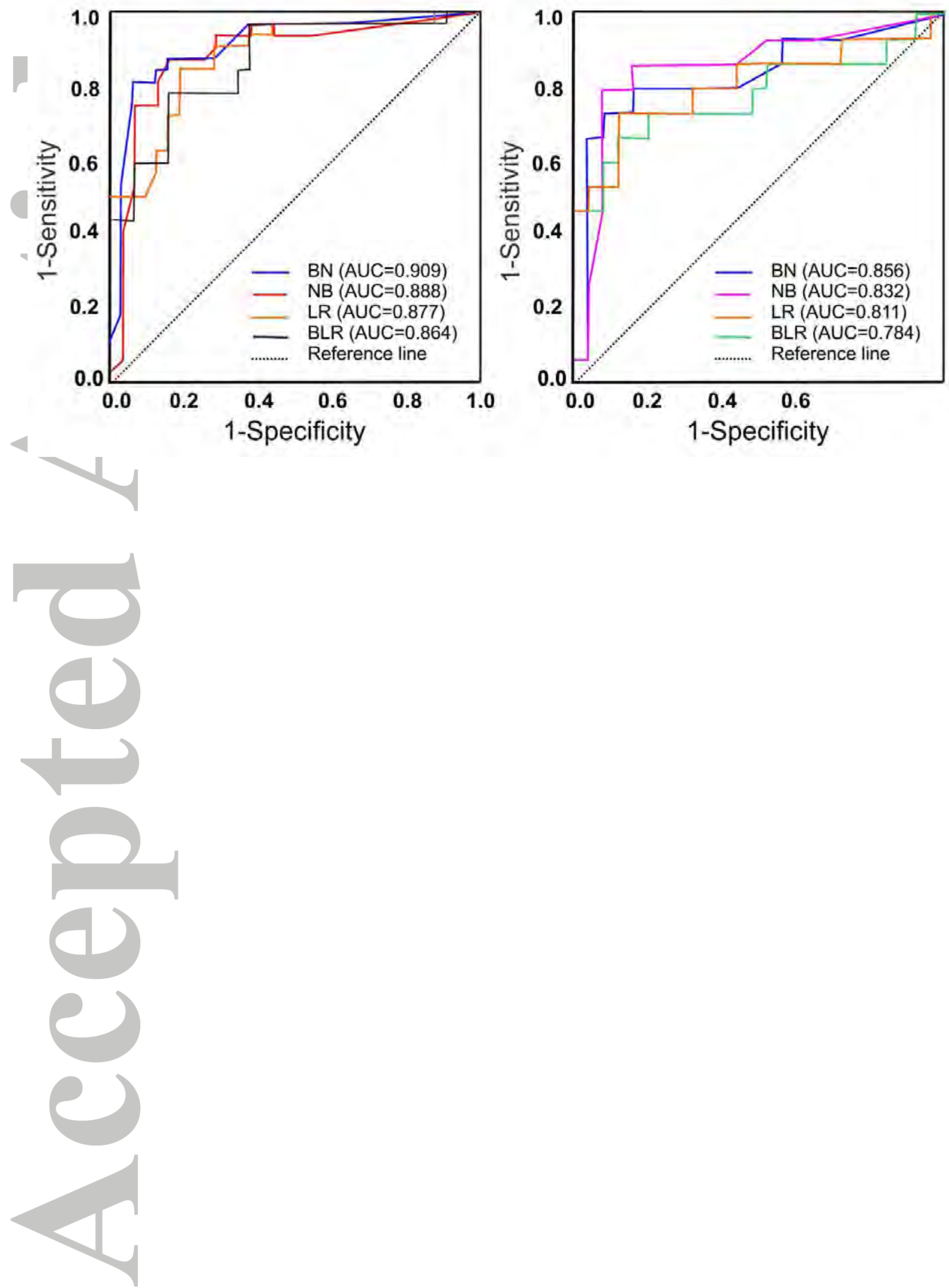